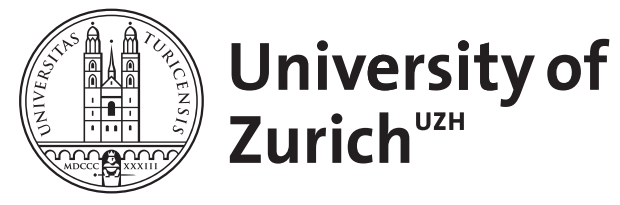

Zurich Open Repository and Archive

University of Zurich

University Library

Strickhofstrasse 39

CH-8057 Zurich

www.zora.uzh.ch

Year: 2015

\title{
Ancestral traits and specializations in the flowers of the basal grade of living angiosperms
}

\author{
Endress, Peter K ; Doyle, James A
}

DOI: https://doi.org/10.12705/646.1

Posted at the Zurich Open Repository and Archive, University of Zurich ZORA URL: https://doi.org/10.5167/uzh-119333

Journal Article

Published Version

Originally published at:

Endress, Peter K; Doyle, James A (2015). Ancestral traits and specializations in the flowers of the basal grade of living angiosperms. Taxon, 64(6):1093-1116.

DOI: https://doi.org/10.12705/646.1 


\title{
Ancestral traits and specializations in the flowers of the basal grade of living angiosperms
}

\author{
Peter K. Endress ${ }^{1}$ \& James A. Doyle ${ }^{2}$ \\ 1 Department of Systematic Botany, University of Zurich, Zollikerstrasse 107, 8008 Zurich, Switzerland \\ 2 Department of Evolution and Ecology, University of California, Davis, California 95616, U.S.A. \\ Author for correspondence: Peter K.Endress,pendress@systbot.uzh.ch \\ ORCID: PKE, http://orcid.org/0001-6622-8196; JAD, http://orcid.org/0002-4083-8786
}

DOI http://dx.doi.org/10.12705/646.1

\begin{abstract}
New morphological and phylogenetic data prompt us to present an updated review of floral morphology and its evolution in the basal ANITA grade of living angiosperms, Chloranthaceae, and Ceratophyllum. Floral phyllotaxis is complex whorled in Nymphaeales and spiral in Amborella and Austrobaileyales. It is unresolved whether phyllotaxis was ancestrally whorled or spiral, but if it was whorled, the whorls were trimerous. The flowers are probably ancestrally bisexual because in most families with unisexual flowers these flowers exhibit rudiments of the opposite sex. Carpels are largely ascidiate and the closure line is short, either transverse or longitudinal. A style is usually absent or, if present, generally short and not plicate. Angiospermy (carpel sealing) is by secretion, rather than postgenital fusion, except in large-flowered Nymphaeales and in Illicium, correlated with unusual fruits. Carpels with a single, median, pendent ovule are probably plesiomorphic. Chloranthaceae and Ceratophyllaceae have an unsettled phylogenetic position, but in some phylogenetic analyses they form a clade, which may be sister to the remaining mesangiosperms (Magnoliidae, monocots, eudicots). This position is supported by their carpel characters, which are similar to those of the ANITA grade and different from those of most other mesangiosperms.
\end{abstract}

Keywords Amborellaceae; angiosperms; ANITA grade; Austrobaileyales; Ceratophyllaceae; Chloranthaceae; floral evolution; floral structure; Nymphaeales; phylogeny

\section{- INTRODUCTION}

A wealth of new information about the nature and evolution of early flowering plants has been assembled in the past thirty years or so, from fossil discoveries, molecular phylogenetics, and developmental and comparative morphology of living plants. Much of this information was summarized by Doyle \& Endress (2014), who presented an updated version of a morphological data matrix for fossil and living angiosperms (not including derived groups within monocots and eudicots) and a discussion of the morphological features and phylogenetic position of relevant Early Cretaceous fossils.

In the global phylogenetic topology of the angiosperms, the two most diverse clades are monocots (Monocotyledoneae) and eudicots (Eudicotyledoneae). A third major clade, the magnoliids (Magnoliidae, including Magnoliales, Laurales, Canellales, and Piperales), is smaller (Cantino \& al., 2007; APG III, 2009). These, together with the much smaller groups Chloranthaceae and Ceratophyllaceae (Ceratophyllum L.), constitute the core angiosperms or Mesangiospermae (Cantino \& al., 2007), which include ca. $99.9 \%$ of living angiosperm species. The mutual relationships of these five clades are not resolved. Below them there is a basal grade (the ANITA or ANA grade), which consists of two or three small clades (Fig. 1) that branch off the lineage leading to mesangiosperms. This global topology of the angiosperms was proposed in 1999 by several groups of molecular phylogeneticists (Mathews \& Donoghue, 1999; Parkinson \& al., 1999; Qiu \& al., 1999; Soltis \& al., 1999) and has been amply corroborated since then by numerous additional studies (Soltis \& al., 2005, in press). The basal grade is the primary topic of this paper. The sister group of all remaining angiosperms consists either of the genus Amborella Baill. alone (Qiu \& al., 1999; Soltis \& al., 1999), followed by Nymphaeales, or of Amborella plus Nymphaeales (Barkman \& al., 2000; Qiu $\&$ al., 2010). Both scenarios are still discussed today based on extended sampling and techniques (Drew \& al., 2014; Xi \& al., 2014; Goremykin \& al., 2015). The next clade in the grade, which is the sister group of mesangiosperms in virtually all analyses, is Austrobaileyales.

The potential relevance of Chloranthaceae and Ceratophyllaceae came into the picture a little later (although the earliest large-scale analysis, of the chloroplast gene $r b c L$, indicated that Ceratophyllaceae were sister to all other angiosperms: Chase \& al., 1993). In many analyses, they appeared as isolated lineages that were separately attached in different positions among mesangiosperms (Fig. 1). For example, in analyses of nearly complete chloroplast genomes (Jansen \& al., 2007; Moore \& al., 2007), Chloranthaceae were sister to magnoliids

Received: 13 Jul 2015 | returned for (first) revision: 12 Sep 2015 | (last) revision received: 24 Sep 2015 | accepted: 24 Sep 2015 || publication date(s): online fast track, 11 Dec 2015; in print and online issues, 31 Dec 2015 || (C International Association for Plant Taxonomy (IAPT) 2015 
and Ceratophyllum was sister to eudicots. However, in the combined morphological and molecular analysis of Doyle \& Endress (2000), which did not include Ceratophyllum, Chloranthaceae were the sister group of all other mesangiosperms, and when Endress \& Doyle (2009) added Ceratophyllum to the tree it formed a clade with Chloranthaceae. This clade has also been found in a growing number of molecular analyses (Antonov \& al., 2000; Duvall \& al., 2006, 2008; Qiu \& al., 2006, 2010; Moore \& al., 2011; Zhang \& al., 2012; Zeng \& al., 2014; Sun $\&$ al., 2015), although its position varies greatly. At present, the relationships of these two groups are still unsettled. However, because they share salient structural features with members of the ANITA grade, and these features are either most likely or potentially ancestral retentions under several mesangiosperm arrangements, we include them in this review. Furthermore, the Chloranthaceae-Ceratophyllum clade is also sister to the other Mesangiospermae in many trees found in the mitochondrial analyses of Qiu \& al. (2006, 2010).

These data on relationships among major angiosperm clades offer a fortunate opportunity to infer ancestral states. Many characters might be polarized if we had relevant information from angiosperm outgroups, but the morphological distance between angiosperms and living gymnosperms (which may form a clade, Acrogymnospermae: Cantino \& al., 2007) is too great for reliable homology assessment, especially in floral characters, and there is essentially no consensus on the most closely related fossil taxa (Rothwell \& al., 2009; Taylor
\& Taylor, 2009; Doyle, 2012). Thus we are largely restricted to a "top-down" approach (Bateman \& al., 2006). In terms of parsimony, if the sister group of all other members of a larger clade (such as Amborella in trees where it is sister to all other angiosperms) has features that differ from those in the rest of the larger clade, and outgroup information is lacking, it is equivocal whether these features are apomorphic or plesiomorphic for the larger clade (such as angiosperms as a whole). In other words, "basal" does not necessarily mean "primitive" (Crisp \& Cook, 2005; Omland \& al., 2008). However, if features are shared by a series of two or more clades that branch off successively below the bulk of the larger clade to which they belong, making up a basal grade (such as Amborella, Nymphaeales, and Austrobaileyales in Fig. 1, which diverge below the mesangiosperms), these features are probably plesiomorphic for the larger clade (again, angiosperms as a whole). Thus, because we are interested in ancestral features of angiosperms, we are lucky to have a basal grade consisting of a few relatively low-diversity lines available for our focus. A more detailed phylogeny and classification of basal angiosperms (Fig. 1, Table 1) illustrates how the clades making up the basal grade are relatively undiverse in terms of numbers of living species and formally recognized higher taxa, in contrast to magnoliids, monocots, and eudicots, whether due to extinction, actual lack of diversification, or both.

Reviews on floral structure with different foci and various new results were provided by Endress (2001, 2004), Endress
Fig. 1. Major clades of the basal grade of angiosperms, including some of the possible positions of Chloranthaceae and Ceratophyllaceae among mesangiosperms to highlight their unresolved placement in the angiosperm phylogenetic tree; magnoliids divided down to orders, and eudicots and monocots without subclades. For references, see text.

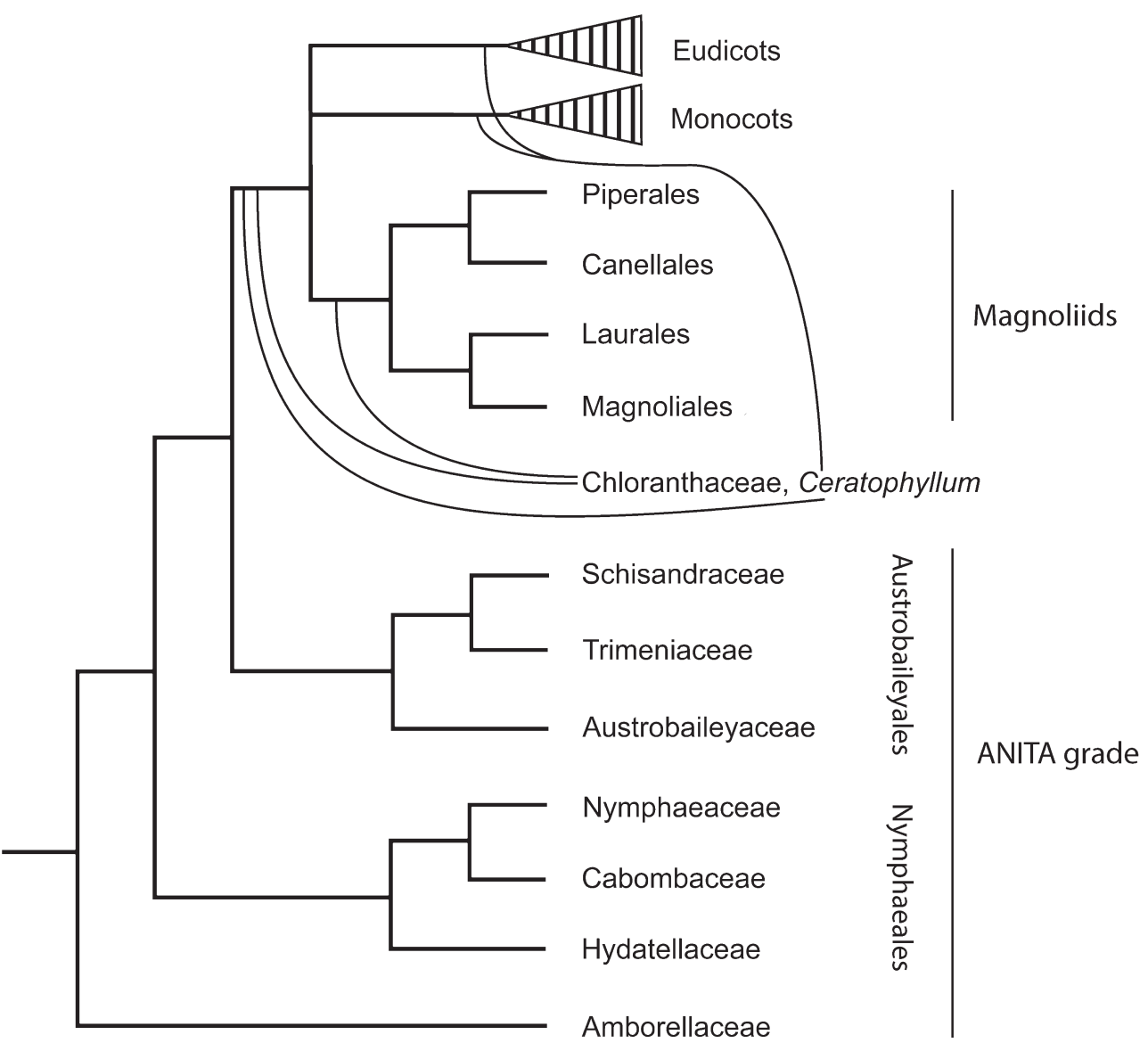


\& Doyle (2009), and Doyle \& Endress (2011). In the last two articles we used parsimony to reconstruct (optimize) the course of evolution of characters on two reference trees, chosen to represent the range of current phylogenetic results. One ("J/M") (Fig. 4) corresponds to the chloroplast genome trees of Jansen $\&$ al. (2007) and Moore \& al. (2007), where Chloranthaceae are sister to magnoliids and Ceratophyllum is sister to eudicots, while the other ("D\&E") (Figs. 3, 4, 6) corresponds to the combined morphological and molecular analysis of Doyle \& Endress (2000), where Chloranthaceae diverge at the base of the mesangiosperms, with the addition of Ceratophyllum as the sister group of Chloranthaceae and rearrangements within major clades based on more recent analyses. Additional results have further modified and improved our knowledge, and a fresh review appears timely. Here we focus on ancestral states of prominent floral structural characters in living flowering plants and on some specializations within the clades making up the basal grade. What do flowers of living basal angiosperms tell us about the early evolution of flowers?

Table 1. Classification and diversity of basal living angiosperms.

Amborellales (1 family, 1 genus, 1 species)

Amborellaceae

Amborella Baill.

Nymphaeales (3 families, 8 genera, 81 species)

Hydatellaceae (1 genus)

Trithuria Hook.f. (12 species)

Cabombaceae (2 genera, 6 species)

Cabomba Aubl. (5 species), Brasenia Schreb. (1 species)

Nymphaeaceae (5 genera, 63 species)

Barclaya Wall. (3 species), Euryale Salisb. (1 species), Nuphar Sm. (16 species), Nymphaea L. (41 species), Victoria Lindl. (2 species)

Austrobaileyales (3 families, 4-6 genera, 78 species)

Austrobaileyaceae (1 genus, 1 species)

Austrobaileya C.T.White

Trimeniaceae ( 1 or 2 genera; more studies necessary through the family)

Trimenia Seem. (2 or more species), Piptocalyx Benth. (2 species, possibly nested in Trimenia)

Schisandraceae (including Illiciaceae, following APG III, 2009)

(2 or 3 genera; more studies necessary in Schisandra and Kadsura)

Schisandra Michx. (25 species), Kadsura Kaempf. ex Juss. (16 species, possibly nested in Schisandra), Illicium Sw. (32 species)

Chloranthales (1 family, 4 genera, 72 species)

Chloranthaceae

Hedyosmum Sw. (44 species), Ascarina J.R.Forst. \& G.Forst. (12 species), Chloranthus Sw. (14 species), Sarcandra Gardner (2 species)

Ceratophyllales (1 family, 1 genus, 4 species)

Ceratophyllaceae

Ceratophyllum L. (4 species)

\section{ANCESTRAL TRAITS OF (LIVING)} ANGIOSPERMS (Figs. 2-7)

Floral phyllotaxis. - An often-addressed feature in basal angiosperms is floral phyllotaxis (see also Endress, 1987a, 2006; Ronse De Craene \& al., 2003; Endress \& Doyle, 2007, 2009). Some angiosperms have different phyllotaxis in the perianth and the fertile organs, such as those Magnoliaceae with whorled tepals but spiral stamens and carpels, and for this reason we have treated perianth and androecium phyllotaxis as separate characters in phylogenetic analyses (Doyle \& Endress, 2000, 2010, 2014; Endress \& Doyle, 2007, 2009). However, there is no such intrafloral variation between whorled and spiral in the taxa considered here.

There are three basic patterns of floral phyllotaxis to consider: (1) spiral, (2) simple whorled, and (3) complex whorled (Staedler \& Endress, 2009). In simple whorls each whorl has the same number of organs, whereas in complex whorls the number increases from whorl to whorl by the intercalation of double positions, where two organs occur at the place where one organ would be expected in a simple-whorled system, and may decrease again toward the floral centre. Complex whorled has often been misinterpreted but is well represented in the ANITA grade, in magnoliids, and in many other angiosperms.

Phyllotaxis of flowers with numerous organs can be best seen by examining young buds when the organs have not yet elongated. In whorled phyllotaxis, the geometric patterns in which the organs are arranged show radial lines (orthostichies) and spiral lines (parastichies) exhibiting the same inclination in both directions (left and right). In spiral phyllotaxis, there are no orthostichies and the inclination of the parastichies is different in the two directions (see Endress, 2006; Endress \& Doyle, 2007; see figures in sections below on Amborellales and Austrobaileyales). In complex whorls there are also orthostichies, but they are interrupted where the number of parts per whorl changes. The difference between simple and complex whorls is shown in Fig. 2.

In the ANITA grade, floral phyllotaxis is constant within orders but divergent between them. It is spiral in Amborella and Austrobaileyales, but simple whorled or more commonly complex whorled in Nymphaeales (Endress, 2001; Schneider $\&$ al., 2003). In complex whorled flowers there is often multiple
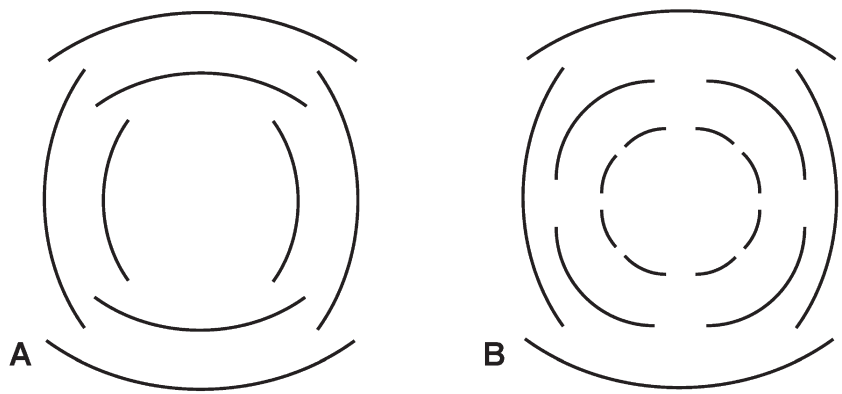

Fig. 2. Types of whorled phyllotaxis. A, simple whorls (all whorls dimerous); $\mathbf{B}$, complex whorls (increase of organ number by double organ positions in some whorls, here from $2 \rightarrow 4 \rightarrow 8$ ). 
doubling of organ positions, in which case the merism changes from whorl to whorl. The basic merism (i.e., that of the first whorl) in Nymphaeales is three (Cabombaceae) or four (most Nymphaeaceae); an evolutionary shift from trimerous to tetramerous apparently occurred within Nymphaeaceae (see below). The whorled floral phyllotaxis in Nymphaeaceae is easily seen in young floral buds. But even in mature flowers the orthostichies that are characteristic for whorled phyllotaxis may still be clearly visible (e.g., Schneider \& al., 2003: fig. 1h, androecium of Nymphaea elegans Hook.).

As seen across angiosperms, simple-whorled patterns occur in flowers with low or medium numbers of organs. By contrast, in flowers with numerous organs two favoured patterns are realized: either spiral or complex whorled, in the latter case implying whorls with double or multiple positions of narrow organs.

Parsimony optimization of perianth (and androecium) phyllotaxis shows that the ancestral character state in angiosperms is equivocal, which is expressed by the hatched signature at the base of the tree in Fig. 3 (Endress \& Doyle, 2007, 2009; Doyle \& Endress, 2011). In this analysis simple and complex whorled are lumped; the distinction between them is largely expressed by another character in the dataset, double positions. As with most characters considered in this article, the same ancestral state is found with both $\mathrm{J} / \mathrm{M}$ and D\&E reference trees. Thus, we do not know whether a spiral or whorled perianth is ancestral. It is possible that both conditions were present side by side in early angiosperm evolution, such that angiosperms exhibited an ancestral polymorphism, with both states expressed to various degrees in the ancestral species (Endress, 1987a). Analyses using maximum likelihood methods, which take into account the greater probability of changes on long branches, may give a better idea of the relative probability of alternative ancestral states in this and similar cases where parsimony yields ambiguous results (Sauquet \& al., 2015).

Comparing the number of floral parts among these taxa poses special problems. In a whorled flower, we can consider the number of parts per whorl (merism) and the number of whorls, but these measures are not applicable in flowers with spiral phyllotaxis. In Doyle \& Endress (2000) and Endress $\&$ Doyle (2009), we treated number of whorls as comparable to number of so-called series (sets of parts that fill the

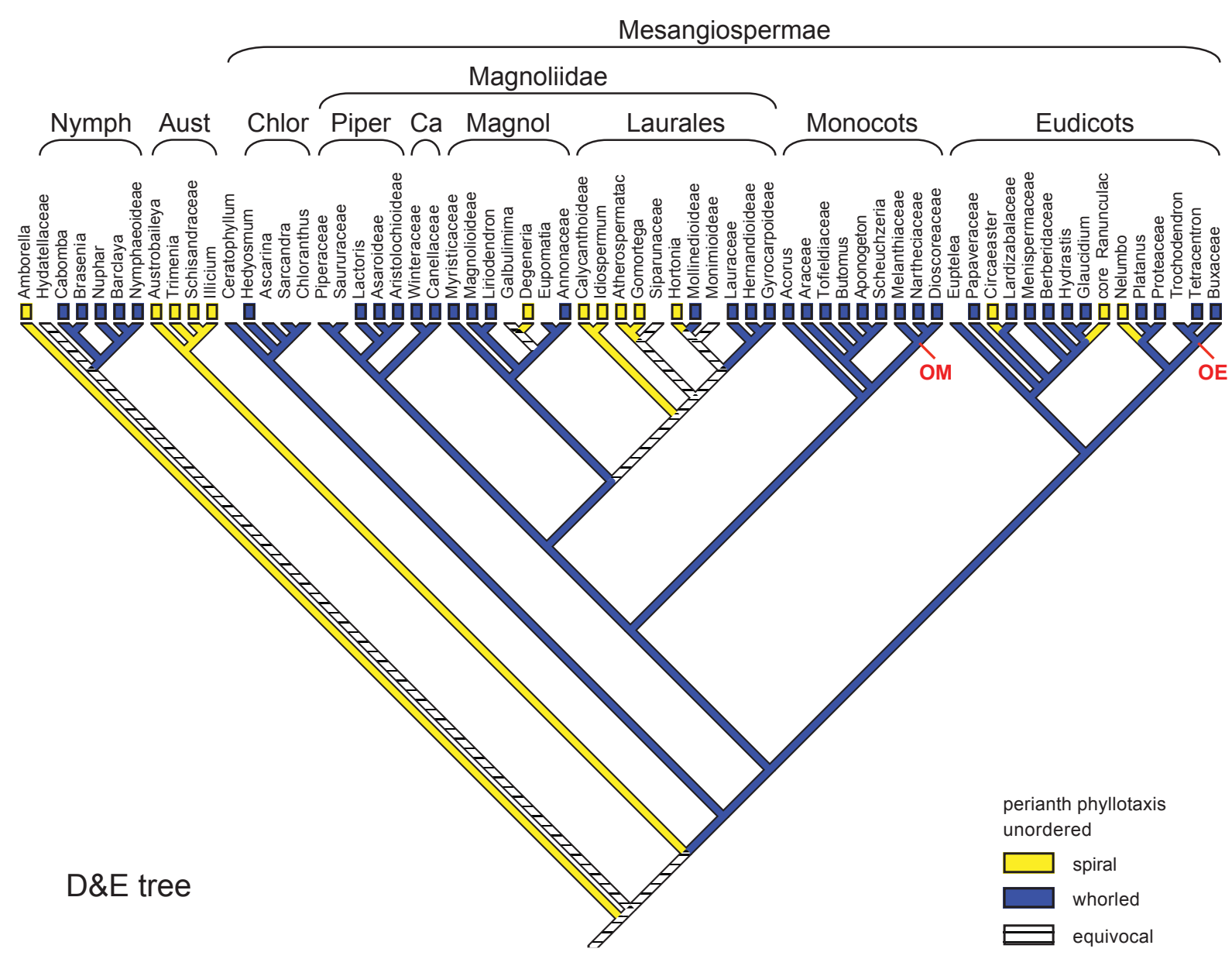

Fig. 3. Most parsimonious course of evolution of perianth phyllotaxis on a tree with mesangiosperm relationships based on combined molecular and morphological data (D\&E tree; Doyle \& Endress, 2000; Endress \& Doyle, 2009). Nymph = Nymphaeales, Aust $=$ Austrobaileyales, Chlor $=$ Chloranthaceae, Piper $=$ Piperales, $\mathrm{Ca}=$ Canellales, Magnol $=$ Magnoliales, $\mathrm{OM}=$ point of attachment of other monocots, $\mathrm{OE}=$ point of attachment of other eudicots. Modified from Endress \& Doyle (2009). 
circumference of the flower) in spiral flowers. Under this treatment, the ancestral angiosperm flower had more than two whorls or series in both the perianth and androecium, and if it was whorled it was trimerous.

Flower buds in the ANITA grade are mostly globular. In bud the outer tepals are shorter (smaller) than the inner tepals in Amborellales and Austrobaileyales, whereas the outer tepals are longer than the inner ones in Nymphaeales (Endress, 2004).

Flower sexuality. - Another commonly asked question is whether flowers of the ancestral angiosperm were bisexual or unisexual. Because Amborella has unisexual flowers, the ancestral state is equivocal in terms of parsimony (Endress \& Doyle, 2009). However, although functionally unisexual flowers occur in six of the nine families considered here, there are only two families, Hydatellaceae and Ceratophyllaceae (with 16 species in total), in which all flowers are unisexual. In the other four families, at least some species exhibit either functionally or morphologically bisexual flowers with a normal position and sequence of stamens and carpels. Significantly, the flowers of Amborellaceae are functionally unisexual, but the female flowers produce one or two sterile stamens following the tepals (Endress \& Igersheim, 2000b; see below), which indicates a bisexual bauplan. The fact that Amborella represents a long branch extending all the way back to the most recent common ancestor of angiosperms is also reason to suspect that the unisexual condition in Amborella is derived, since more change is likely to have occurred on such a long branch than on the short internal branches leading to the remaining angiosperms.

Another character related to sexuality is the relative timing of maturation of the male and female organs, an important aspect of breeding systems. It is of interest that bisexual flowers in the ANITA grade are all protogynous, which is also the nearly universal state in magnoliids and appears to be the ancestral mechanism in angiosperms for avoiding self-pollination (Bernhardt \& Thien, 1987; Thien \& al., 2000; Endress, 2010). Protandry evolved only in flowers with pronounced stamen filaments and (especially in monosymmetric flowers) with well-developed styles. Such differentiation of stamens and carpels is rare in the ANITA grade and magnoliids (Endress, 2010).

Carpels, angiospermy. - In a long-term study on gynoecium structure in all families of basal angiosperms (including the taxa considered here and magnoliids, "basal" monocots, and "basal" eudicots) by Igersheim and Endress (e.g., Igersheim \& Endress, 1997; Endress \& Igersheim, 2000a) it was found (1) that most carpels in the ANITA grade are pronouncedly ascidiate (sack- or bottle-shaped, with only a very restricted morphological entrance into the inner space of the carpel), rather than plicate (folded down the middle), and (2) that carpel sealing (i.e., angiospermy) is not by postgenital fusion (where the carpel margins come together in development and their immature epidermises dedifferentiate and fuse) but merely by secretion. Exceptions in the ANITA grade are rare (see below). Already Leinfellner (1969) emphasized that carpels of basal angiosperms tend to be peltate (a term that includes ascidiate) rather than plicate, as widely assumed, although most of the taxa he studied were not from the ANITA grade, but rather from the magnoliids, and thus he did not encounter extremely ascidiate forms (except in Schisandraceae in the Austrobaileyales and some Winteraceae in the magnoliids). Endress found extremely ascidiate carpels in earlier case studies of members of the ANITA grade, such as Austrobaileyaceae (Endress, 1980b, 1983), Trimeniaceae (Endress \& Sampson, 1983), and Amborellaceae (Endress, 1986), and in Chloranthaceae (Endress, 1971, 1987b), to which Endress (2005) added Cabombaceae. In an abstract, Endress \& Igersheim (1997b) mentioned six families with carpels sealed by secretion, all in the ANITA grade (before the grade was recognized in molecular studies) plus Chloranthaceae and Ceratophyllaceae, and none in the magnoliids. By constrast, in most families of magnoliids and other Mesangiospermae, carpel shape is not ascidiate, or only partially ascidiate, and carpel sealing is predominantly by postgenital fusion. Derived, uniovulate Laurales might be viewed as a partial exception, in which the basal portion of the carpel, where the ovule is attached, is ascidiate, but the apical portion is plicate, a condition that we call intermediate.

A consequence of largely free and strongly ascidiate carpels is that an intragynoecial compitum, i.e., an area within the gynoecium where pollen tubes can grow from the stigmatic surface of one carpel to the ovule(s) of another, is lacking (Endress \& Igersheim, 2000a). Alternative adaptations within the basal lines are discussed below.

Parsimony optimization of the carpel form character on both trees used by Endress \& Doyle (2009) indicates that pronouncedly ascidiate carpels are ancestral (Fig. 4). If Chloranthaceae and Ceratophyllum form a clade at the base of the mesangiosperms (D\&E tree, Fig. 4A), the ascidiate carpels of these taxa are homologous (symplesiomorphic) with the very similar carpels in the ANITA grade, and the origin of plicate carpels is a synapomorphy of the remaining mesangiosperms (in some cases reversed or modified later within the clade, as noted above). However, if Chloranthaceae and Ceratophyllum are linked with magnoliids and eudicots, respectively $(\mathrm{J} / \mathrm{M}$ tree, Fig. 4B), it is equivocal whether their ascidiate carpels are retained from the basal grade or represent reversals from plicate. Character optimization also shows that carpel sealing was originally by secretion, and not by postgenital fusion (Endress \& Doyle, 2009). As discussed further below, carpel sealing by postgenital fusion evolved in two derived groups of the ANITA grade. The inferred ancestral number of carpels is not high, in the range of two to five.

An additional unusual feature in carpel morphology in the ANITA grade was recognized more recently (Endress, 2015). It is what happens before or when the carpel closes and how the resulting closure slit is shaped. One mode of closure is shown in the half-ascidiate (intermediate) carpel of a mesangiosperm (Fig. 5A-C; for specimens used for figures, see Appendix 1). The upper part of the carpel closes by folding into a tubular style, which forms an internal confined pollen tube transmitting tract, in which pollen tube growth and competition take place. Closing commonly begins at mid-length of the style. At the lower end of the closure area, a short transverse slit may also form. Thus the entire line of closure has the shape of an inverted " $T$ " or "Y". 

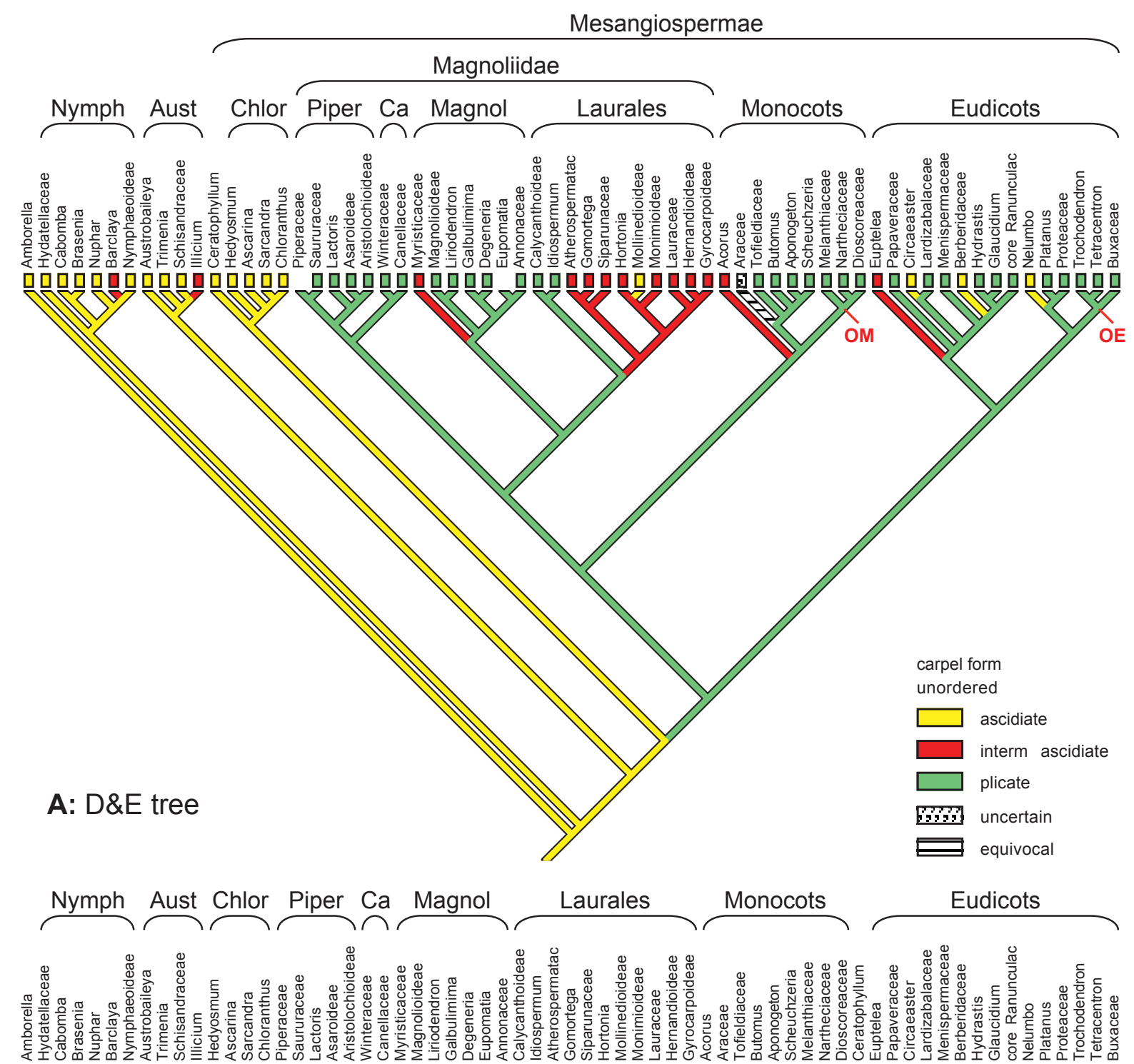

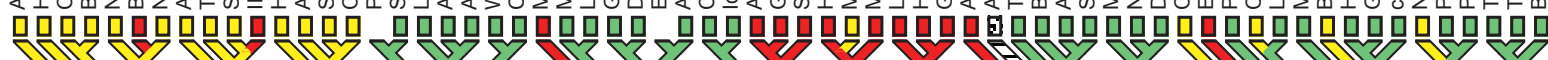

Fig. 4. A, most parsimonious course of evolution of carpel form on the D\&E tree (see Fig. 3); B, evolution of carpel form on a tree with mesangiosperm relationships based on nearly complete chloroplast genomes $(\mathrm{J} / \mathrm{M}$ tree; Jansen \& al., 2007; Moore \& al., 2007). - Abbreviations as in Fig. 3. Modified from Endress \& Doyle (2009).

\section{B: J/M tree}

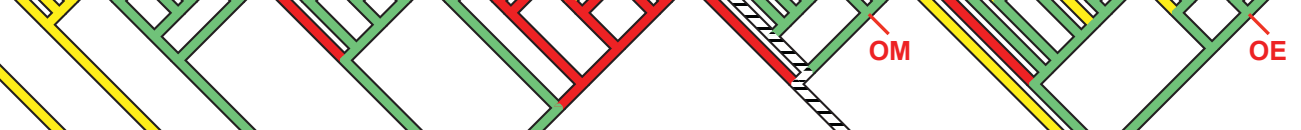


The most common shapes of the closure line of free carpels in angiosperms are either this type with a short transverse extension at the lower end (inverted " $T$ ") or a simple longitudinal slit. If the pattern is an inverted "T", the carpel usually has an ascidiate ovary and the transverse extension of the slit is at the upper end of the ovary.

In the ANITA grade the situation is different, and the following four patterns are mainly realized (Fig. 5D-N): (1) very short longitudinal slit, style lacking (Fig. 5D); (2) very short longitudinal slit at the end of the style (Figs. 5E, L, N, 10D; (3) transverse slit, style lacking (Fig. 5F, H-J); (4) transverse slit, style present, but unifacial or flat (Fig. $5 \mathrm{G}, \mathrm{K}, \mathrm{M}$ ). These patterns are intimately connected with the fact that these carpels are all ascidiate but can close in different ways. The two most common types in the ANITA grade (plus Chloranthaceae and Ceratophyllaceae) are a simple transverse slit at the level of the ovary or a short longitudinal slit in the upper part of a carpel. It might be suggested that this diversity is a sign that the ascidiate type is heterogeneous, e.g., derived in some cases by reduction from the intermediate (basally ascidiate, apically plicate) type. However, this is unlikely, since deviations from the ascidiate carpel are rare in the ANITA grade; the only examples are the intermediate carpels of Barclaya Wall. and Illicium L., both taxa that are well nested within their respective orders.
In the ANITA grade, and Chloranthaceae and Ceratophyllum, a style is commonly lacking. If there is a style-like apical extension, it is never folded or rolled inward. Thus there is no extensive confined pollen tube transmitting tract. The only exception is Illicium, in which the ovary and style are largely plicate, a condition that later plays a role in the unusual explosive expulsion of the seed (Romanov \& al., 2013). In other cases with a style-like extension, it is flat and not folded (Hedyosmum Sw.) or unifacial (Ceratophyllum, Fig. 5G, Victoria Lindl., Fig. 5M), or, if it is closed, it is not folded but rather represents just the tubular elongated upper ascidiate zone (Cabombaceae, Austrobaileya C.T.White, and Schisandra Michx. s.1.; Fig. 5E) (e.g., Endress, 1971, 1983, 2005; Shamrov, 2009; Galati \& al., 2015). However, Endress (1994) and Iwamoto \& al. (2003) interpreted the style-like extension in Ceratophyllum as a ventral outgrowth of the carpel, which would imply that it is not a normal style. Endress (1994) based this on the observation that the extension is on the side of the carpel bearing the ovule, which would be expected to be ventral, while Iwamoto \& al. (2003) showed that early in carpel development there is a gland located opposite the extension that is similar to the gland that sits at the apex of the stamens and vegetative organs. Illustrations by Shamrov (2009) also show that the ovule is positioned on the side with the style-like
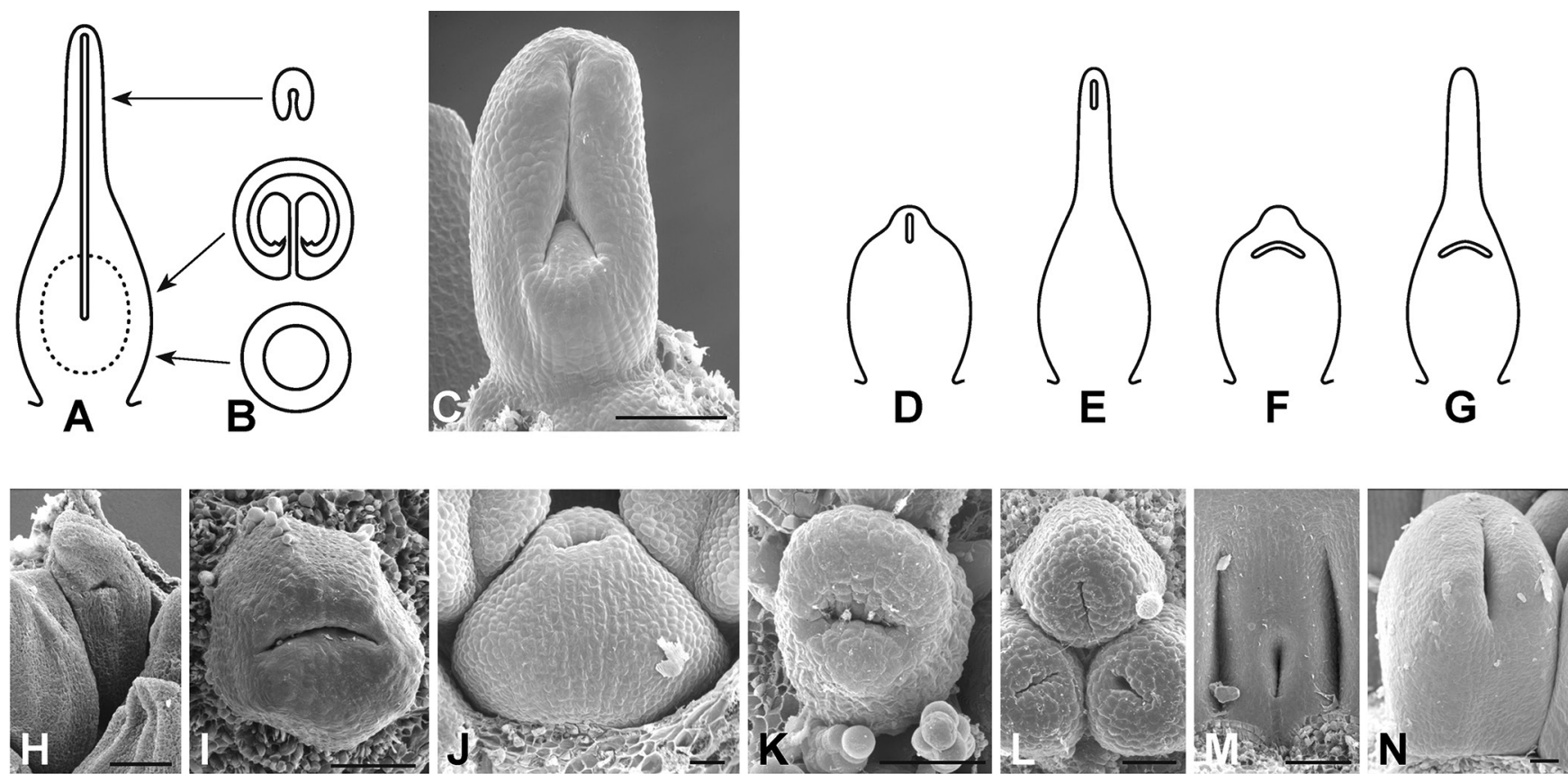

Fig. 5. Carpel closure patterns in angiosperms. A, schematic drawing of carpel of a mesangiosperm, from ventral side, with longitudinal slit of closure. B, transverse sections at three different levels (upper in the plicate style, middle in the plicate zone of the ovary, lower in the ascidiate zone of the ovary, as shown by arrows). C, closure of young carpel in Laurus nobilis L. (Magnoliidae, mesangiosperms), SEM showing longitudinal and basal transverse slit (closure process beginning at mid-level of the longitudinal slit). D-G, schematic drawings of carpel closure patterns in the basal ANITA grade, Chloranthaceae, and Ceratophyllaceae: D, Schisandraceae; E, Cabombaceae, Austrobaileyaceae; F, Amborellaceae, Hydatellaceae, Trimeniaceae, Chloranthaceae; G, Hedyosmum, Ceratophyllaceae. H-N, SEMs illustrating closure patterns in ascidiate carpels: H-K, carpels with short transverse slit; H, Amborella trichopoda; I, Trimenia papuana Ridl.; J, Chloranthus erectus (Buch.-Ham.) Verdc.; K, Ceratophyllum demersum L.; L-N, carpels with short longitudinal slit: L, Cabomba furcata Schult. \& Schult.f.; M, Victoria cruziana A.D.Orb. (carpel fused to floral cup, with incipient unifacial tip above ventral slit); N, Austrobaileya scandens C.T.White. - Magnification bars: C, H, I, $\mathrm{L}-\mathrm{N}=100 \mu \mathrm{m} ; \mathrm{J}, \mathrm{K}=50 \mu \mathrm{m}$. 
extension (although he interpreted the gynoecium as composed of two united carpels).

Simple transverse ventral slits are especially prominent. They occur when the carpel has a single median ovule and a typical plicate style is absent. Carpels of this type are especially common in the ANITA grade and may be ancestral, as discussed below. They characterize Amborellaceae, Hydatellaceae, Trimeniaceae, Chloranthaceae, and Ceratophyllaceae (Fig. 5F-K). By contrast, free carpels with several ovules, as in Cabombaceae, Austrobaileya, and Schisandra s.1., have a short median longitudinal slit (Fig. 5D, E, L-N).

Ovules. - A recurrent feature in all the lines considered here is carpels with a single median, pendent ovule (Amborellaceae, Hydatellaceae, Trimeniaceae, Chloranthaceae, Ceratophyllaceae; Endress \& Igersheim, 2000a; Figs. 6, 7). This condition also occurs in Early Cretaceous and Cenomanian fossils that appear to be related to clades of the ANITA grade and Chloranthaceae, such as Anacostia Friis \& al., Appomattoxia Friis \& al., the Asteropollis Hedlund \& Norris plant, Canrightia Friis \& Pedersen, Couperites Pedersen \& al., the Pennipollis Friis \& al. plant, and Zlatkocarpus J. Kvaček \& Friis (see review in Doyle \& Endress, 2014). However, other Nymphaeales and other Austrobaileyales have carpels with more than one ovule. Parsimony optimization indicates that one pendent ovule is ancestral on both trees (Fig. 6). The ovules themselves are bitegmic and crassinucellar (except in Ceratophyllum, see below), and predominantly anatropous, except in groups with particular locule architectures, as discussed below under "Amborellales".

Embryo sacs. - The embryo sac in Nymphaeales and Austrobaileyales is remarkable in being 4-nucleate and 4-celled, so that the endosperm (which is formed by normal double fertilization) is diploid (Williams \& Friedman, 2002, 2004; Friedman \& al., 2003; Friedman \& Williams, 2004; Tobe \& al., 2007; Rudall $\&$ al., 2008; Friedman \& Ryerson, 2009). Thus this embryo sac has only two rounds of mitotic divisions, and not three as in most other angiosperms. This feature was reported earlier in some representatives of Nymphaeales and Austrobaileyales, before their key phylogenetic position was recognized (e.g., in Schisandra: Swamy, 1964; Cabomba Aubl.: Batygina \& al., 1982; Galati, 1985; Nymphaea L.: Winter \& Shamrov, 1991a; Van Miegroet \& Dujardin, 1992; Orban \& Bouharmont, 1998; Povilus \& al.,

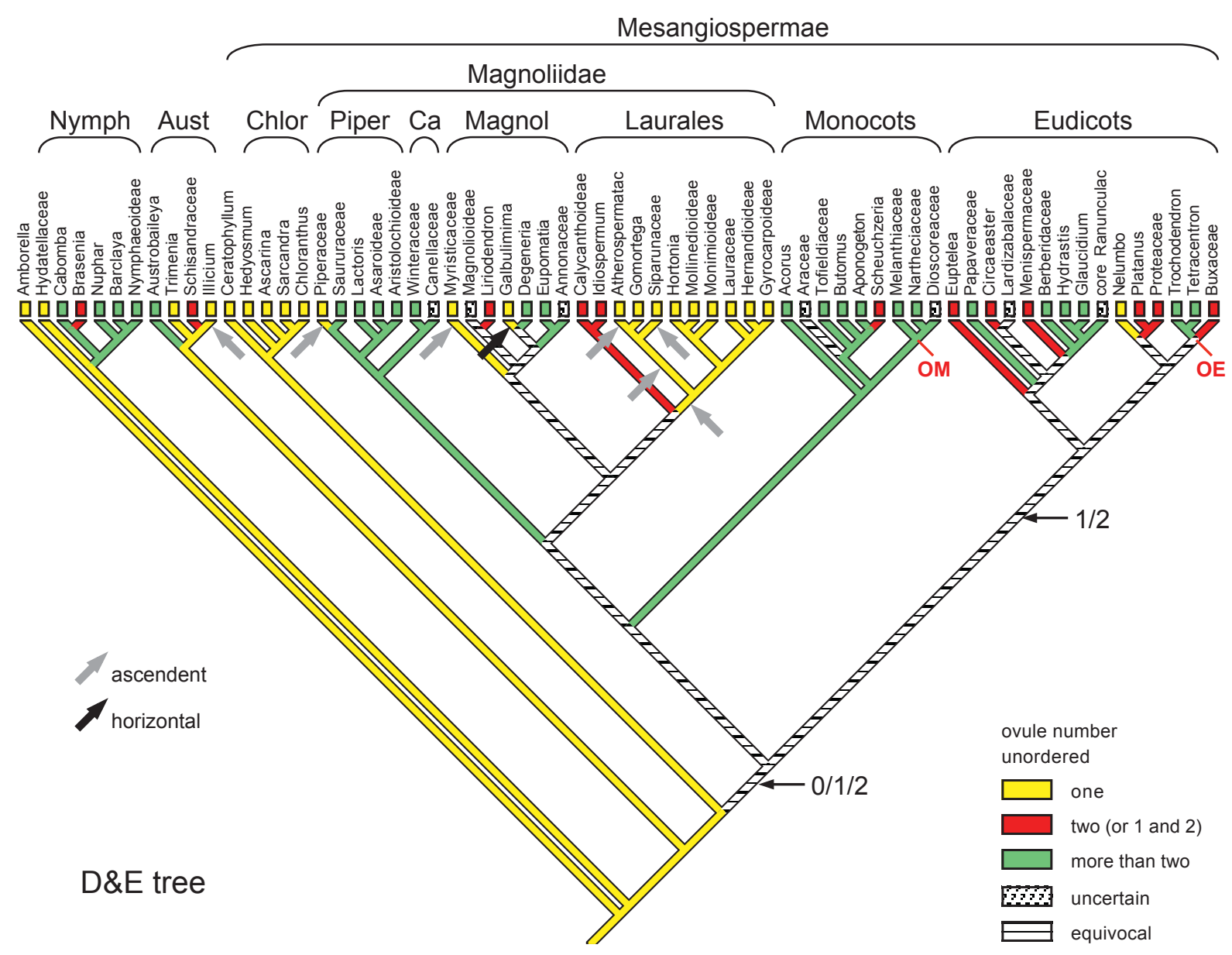

Fig. 6. Most parsimonious course of evolution of number of ovules per carpel on the D\&E tree (see Fig. 3). In most groups with uniovulate carpels, the ovule direction is pendent; exceptions are indicated by grey arrows for ascendent direction, black arrow for horizontal direction. Abbreviations as in Fig. 3. Modified from Endress \& Doyle (2009). 
2015; Zini \& al., 2015; Victoria: Winter \& Shamrov, 1991a; Zini \& al., 2015; Nuphar Sm.: Winter \& Shamrov, 1991b; Barclaya: Winter, 1993). However, the situation in Amborella is different. Tobe \& al. (2000) reported that its embryo sac has three rounds of mitotic divisions, leading to a conventional Polygonum-type embryo sac, but later it was found to have a 9-nucleate, 8-celled embryo sac, resulting from an additional division of one cell of the egg apparatus (Friedman, 2006; Friedman \& Ryerson, 2009). By contrast, an 8-nucleate and 7-celled embryo sac (thus the normal Polygonum type of most other Mesangiospermae) was found in Chloranthaceae (Edwards, 1920; Yoshida, 1957, 1959, 1960; Vijayaraghavan, 1964) and Ceratophyllaceae (De Klercker, 1885; Strasburger, 1902; Jędrychowska \& Sroczyńska, 1934; Shamrov, 1983, 1997). From this systematic distribution, the 4-nucleate embryo sac could be ancestral for angiosperms, with independent origins of the 8- and 9-nucleate types, but in terms of parsimony this is ambiguous.

As noted by Orban \& Bouharmont (1998), a number of older studies on Nymphaeaceae reported 8-nucleate embryo sacs (they cited 14 papers). However, as all newer studies have found the 4-nucleate pattern, it is most likely that other reports were based on erroneous interpretations of the studied microtome sections (discussed by Friedman \& Williams, 2003). As noted, a functional consequence of the 4-nucleate embryo $\mathrm{sac}$ is the fact that the endosperm is diploid in Nymphaeales and Austrobaileyales, rather than triploid as in most angiosperms (Friedman \& Williams, 2003, 2004). If this condition is ancestral, a shift to triploid endosperm occurred in the line to mesangiosperms; whether this was related to their vastly greater diversity is a topic for future study.

Pollen tube growth. - Williams $(2008,2009)$ has shown that pollen tubes grow relatively slowly in the transmitting tract of the carpels in the ANITA grade as compared to other angiosperms, with a speed of growth intermediate between that in gymnosperms and Mesangiospermae. Pollen tube transmitting tracts are short because long styles are lacking (Endress,
2015). However, the growth pattern of the pollen tubes, in which callose plugs are formed intermittently and keep the active part of the pollen tube constantly short even in long pollen tubes, and pollen tube growth is restricted to on or in the cell walls (without destroying the cells) or in secretion outside of the gynoecium tissue, is the same in the ANITA grade as in Mesangiospermae but differs markedly from the pattern in living gymnosperms (Willliams, 2008, 2009; Williams \& al., 2010; Taylor \& Williams, 2012). Pollen germination time is comparable to that in mesangiosperms and much faster than in gymnosperms (Williams, 2012).

Fruits. - Fruits are indehiscent in Amborella, Austrobaileyales (except Illicium), Chloranthaceae, and Ceratophyllaceae. If they are fleshy, they are either berries (Austrobaileya, Trimeniaceae, most Chloranthaceae; Endress, 1980b, 1987b; Endress \& Sampson, 1983) or rarely drupes (Amborella; Bobrov \& al., 2005; Hedyosmum; Endress, 1971). However, the fruits open in many Nymphaeales and in Illicium (Schisandraceae), although with different mechanisms. In Nymphaeales, they commonly open under water or close to water; the fruit walls remain soft and the mechanical tissue is not extensive (Schneider \& Williamson, 1993; Williamson \& Schneider, 1993; Sokoloff \& al., 2008, 2013; Yatzenko \& al., 2012). The fruits rupture from internal pressure by the growing seeds, e.g., in Victoria (Schneider, 1976), or simply by rotting, e.g., in Brasenia Schreb. (Van der Vlugt, 1996). In Illicium the seeds are expelled explosively by deformation of the thick, woody carpel flanks (Romanov \& al., 2013). Based on the dataset of Doyle \& Endress (2014), indehiscent fruit is probably the ancestral state in angiosperms (Endress, 1996).

To summarize, parsimony optimization of floral characters on trees in which the ANITA groups form a basal grade implies that the flower in the most recent common ancestor of living angiosperms had more than two whorls or series of tepals and stamens, which were trimerous if they were whorled, and $2-5$ ascidiate carpels containing a single pendent, bitegmic
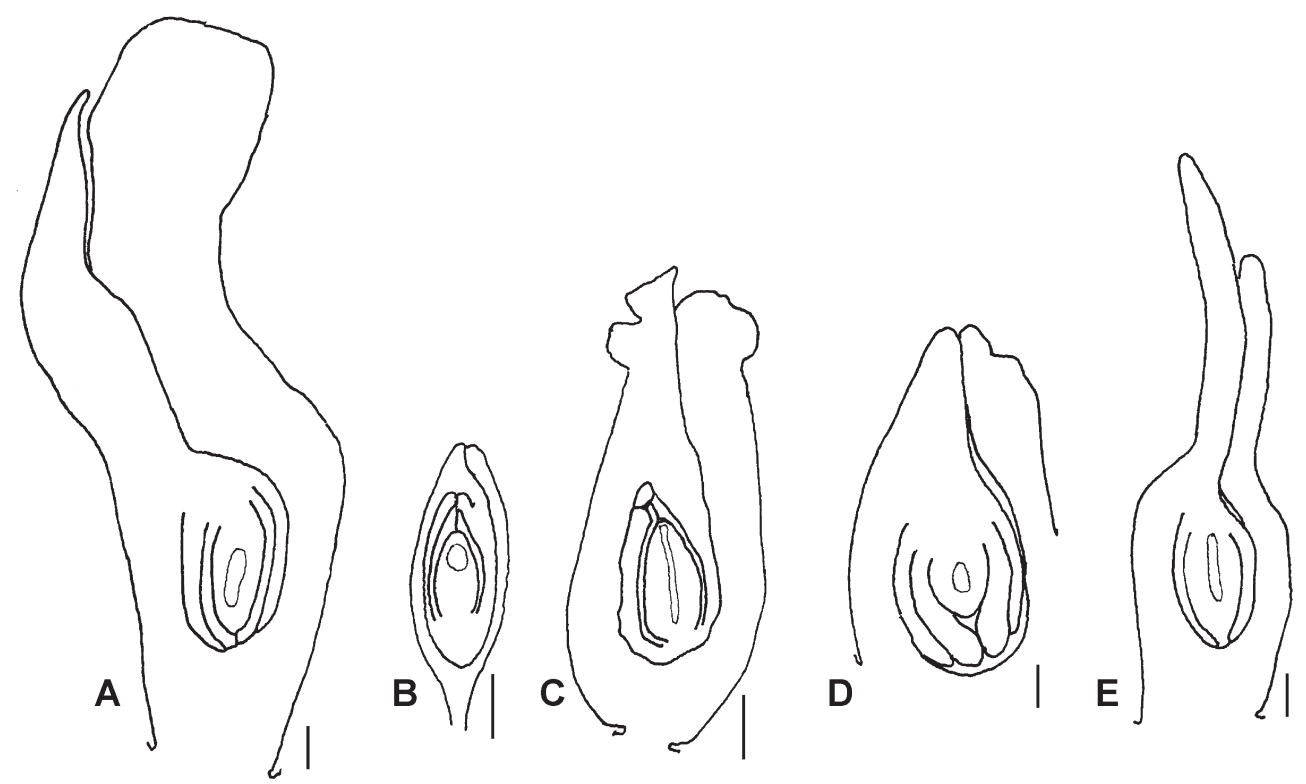

Fig. 7. Carpels and ovules in uniovulate carpels, median LS, one example from each of the five orders treated here. A, Amborella trichopoda (redrawn and simplified from Endress \& Igersheim, 2000b: fig. 9L); B, Trithuria inconspicua Cheeseman (redrawn and simplified from Hamann, 1975: fig. 39); C, Trimenia neocaledonica Baker f. (redrawn and simplified from Endress \& Sampson, 1983: fig. 31); D, Chloranthus erectus (redrawn and simplified from Endress, 1987b: fig. 173); E, Ceratophyllum demersum (original). - Magnification bars: A, B, D, E = $100 \mu \mathrm{m}$; $\mathrm{C}=500 \mu \mathrm{m}$ 
ovule. The most parsimonious ancestral states in floral sexuality and phyllotaxis are equivocal in the absence of outgroup information.

\section{MAIN CLADES OF THE BASAL LIVING ANGIOSPERMS AND THEIR SPECIAL- IZATIONS (DERIVED TRAITS) (Figs. 8-12)}

As mentioned earlier and summarized in Table 1, the basal grade of angiosperms consists of three orders, or five if Chloranthales and Ceratophyllales are included. They contain 7-9 families, 13-20 genera (depending on circumscription of genera in Austrobaileyales and inclusion of Chloranthaceae and Ceratophyllum), and 160-236 species. Five of the nine families contain only a single genus, and two families are unispecific. The most species-rich families (but still with only between 50 and 100 species) are Nymphaeaceae, Schisandraceae, and Chloranthaceae. Numbers of genera and species are from "The Plant List" (http://www.theplantlist.org), with corrections for Nymphaeaceae (inclusion of Nymphozanthus Rich. and Ropalon Raf. in Nuphar, Hydrostemma Wall. in Barclaya).

Amborellales (Amborellaceae, Amborella). - Because most molecular analyses place Amborella at the very base of the angiosperm tree, parsimony cannot be used to determine whether features in which Amborella differs from other nearbasal angiosperms are ancestral or derived. However, as argued in the discussion of its unisexual flowers, some remarks on its other floral features may be useful.

In both male and female flowers of the sole living species, Amborella trichopoda Baill., the phyllotaxis is spiral (Fig. 8A, B); as discussed above, it is equivocal whether this arrangement is ancestral or derived from whorled. The male flowers are small, only a few millimeters in diameter, and have a moderate number of tepals and stamens. The stamens are presented on a flat platform, which originates by peripheral rupturing of a shallow floral cup when the flower opens (Fig. 8B-D). The floral cup is less conspicuous in female flowers because they have fewer organs and are smaller. Interestingly, as previously discussed, the female flowers are morphologically bisexual. They usually have one or two stamens, which develop up to meiosis but then stop development (Fig. 8C), so pollen is not formed. A rupturing floral cup forming a flat platform is not present in flowers of other ANITA lines, and it is tempting to assume that this is apomorphic in Amborella. If so, perhaps it evolved together with a moderate increase in number of floral parts, especially stamens. Notably, a similar floral cup also occurs at fruiting time in some magnoliids (Monimiaceae, Siparunaceae: Laurales; Endress, 1980a). The shared occurrence of a plate-like floral base to present flowers or fruits together with the simple, uniovulate carpel was probably a main reason why Amborella was positioned close to or within Monimiaceae in the premolecular era (e.g., Perkins, 1925).

An unusual developmental feature is that the floral organs are especially crowded in bud so that they become irregularly compressed and are difficult to study during this phase (Endress \& Igersheim, 2000b; Posluszny \& Tomlinson, 2003;
Buzgo \& al., 2004). They show a high degree of imprinted shapes (see Endress, 2008b). No other member of the ANITA grade is known to have this feature.

Ovules of Amborella have puzzled authors who tried to characterize them, and they have been described in the literature as anatropous, orthotropous, or orthotropous of a different kind than, e.g., in Piperaceae (Yamada \& al., 2001). There are two different problems posed by these uniovulate carpels, in which the placenta is ventral and the ovule fills the locule. The first is that, as discussed in Endress (2011), an exactly orthotropous shape is only possible in a uniovulate carpel or unilocular gynoecium if the ovule has an exactly basal position (such as, e.g., in Piperaceae) or if the locule is wide leaving ample free space around the developing ovule (e.g., some Araceae). Otherwise a curvature in the basal part of the ovule is unavoidable. The second is that, because of lack of space in the locule in early stages of ovule development, the ovule is not able to adopt an anatropous curvature in Amborella (this is also true in Chloranthaceae and Ceratophyllaceae). Thus the ovules in Amborella have a basal curvature but are otherwise orthotropous. To understand ovule structure better, it is important to study ovules not in isolation but in combination with the architecture of the ovary locule (Endress, 2011). Whether the orthotropous ovule of Amborella is ancestral or derived is equivocal in terms of parsimony; this question might be addressed by consideration of potential fossil outgroups of angiosperms, but this is outside the scope of the present article (see Endress \& Doyle, 2009; Doyle, 2012).

Nymphaeales. - We have long been familiar with giantflowered waterlilies with numerous floral parts (Davis \& al., 2008) and, since recently (Saarela \& al., 2007), with the minuteflowered, one-parted Hydatellaceae, now considered to consist of the single genus Trithuria Hook.f. (Sokoloff \& al., 2008). Most probably neither of these extremes is ancestral in Nymphaeales. Their most recent common ancestor, assuming it had the inferred ancestral states for Cabombaceae and Nymphaeaceae in characters that are inapplicable in Trithuria (e.g., perianth), can be reconstructed as having a perianth and an androecium of more than two trimerous whorls and 2-5 free, ascidiate carpels containing a single pendent, anatropous, and bitegmic ovule. This is identical to the reconstructed flower in the most recent common ancestor of angiosperms as a whole if this had whorled phyllotaxis and anatropous ovules, although presumably the plant already had the vegetative adaptations to an aquatic habitat (loss of secondary growth, etc.) that are shared by all Nymphaeales. Inferred changes in floral morphology within the order are shown in Fig. 9A.

Hydatellaceae. - Hydatellaceae (Trithuria) form tiny grass-like plants. They were earlier thought to be monocots and were classified in Centrolepidaceae (Poales) because of superficial similarities. However, Hamann $(1975,1976)$ recognized that they were not related to Centrolepidaceae nor Poales by careful structural studies and described them as a new family incertae sedis. It was not until Saarela \& al. (2007) that molecular and morphological analyses detected their position as sister to all other Nymphaeales. Their superficially flowerlike reproductive structures are interpreted as inflorescences 
made up of miniaturized unisexual flowers that consist of a single stamen or a single carpel containing a single anatropous, bitegmic ovule (Fig. 7B; Hamann, 1975, 1976; Rudall \& al., 2007). It has been suggested that these structures may represent a primitive, pre-floral or "nonfloral" state (Rudall \& al., 2009), but parsimony optimization implies instead that they are derived. The female flowers have several long, uniseriate stigmatic hairs on top of the gynoecium, whose large size is disproportionate in view of the minute flowers; pollen tubes grow within the cell walls of these hairs (Prychid \& al., 2011; Taylor \& Williams, 2012).

Cabombaceae. - Compared to Hydatellaceae and Nymphaeaceae, the flowers of Cabombaceae (Cabomba, Brasenia) look much more "normal", as they are bisexual and medium
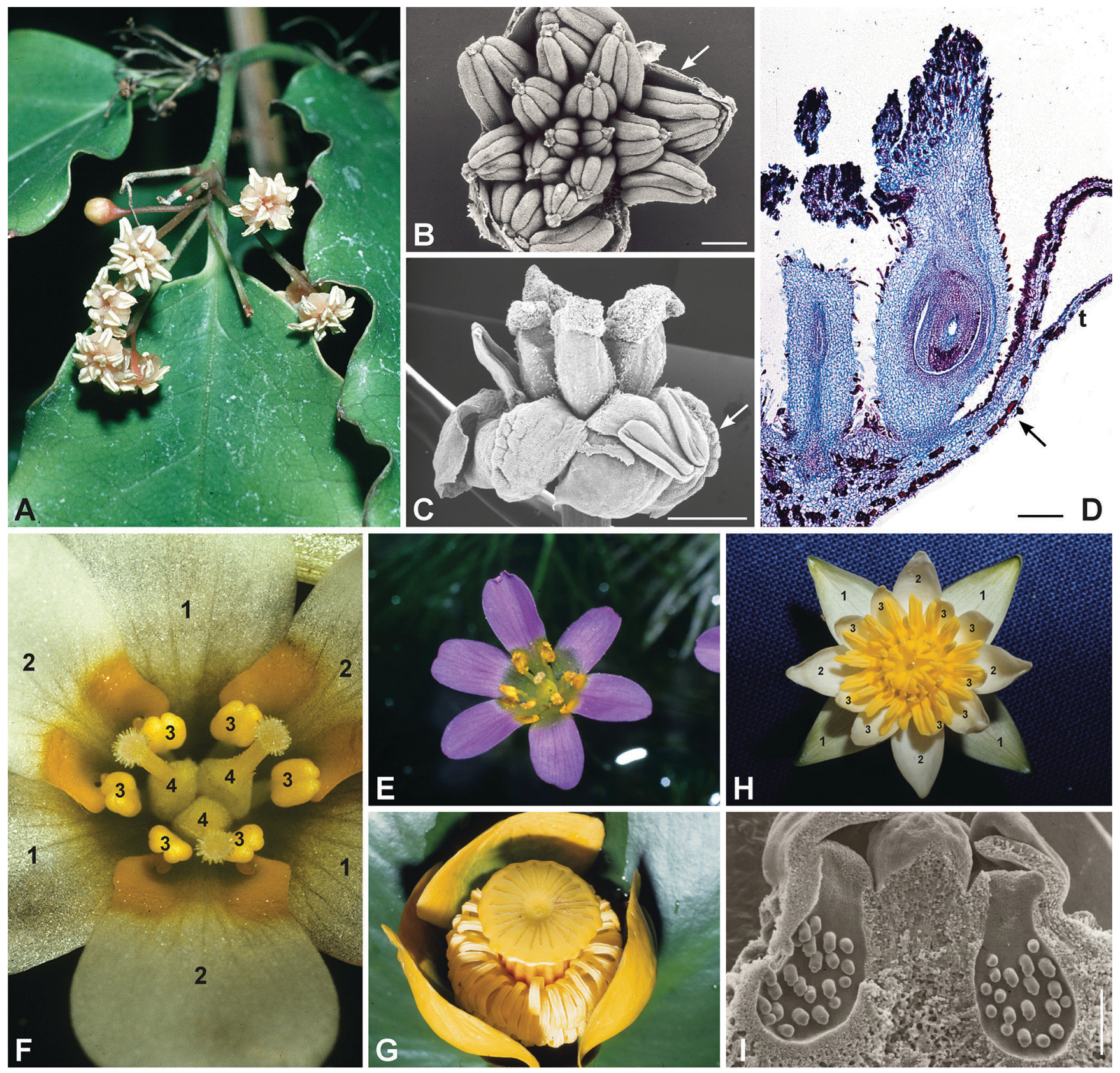

Fig. 8. Amborellales and Nymphaeales. A-D, Amborella trichopoda: A, male inflorescence; B, freshly opened male flower, from above, anthers still closed, torn floral cup visible (arrow); C, female flower, from the side, on the right side a reflexed sterile stamen (arrow); $\mathbf{D}$, longitudinal section of female anthetic flower, a carpel in approximately median section, ventral side on the left (arrow points to floral cup, $t=$ tepal). E-F, Cabombaceae: E, Cabomba furcata; F, Cabomba caroliniana A.Gray, flower with trimerous whorls, androecium forming a complex whorl with double positions; all floral organs numbered according to whorl. G-I, Nymphaeaceae: G, Nuphar advena (Aiton) W.T.Aiton; H-I, Nymphaea tetragona Georgi; $\mathbf{H}$, anthetic flower, from above; perianth organs in each whorl numbered to show single and double positions. — Magnification bars: $\mathrm{B}, \mathrm{I}=500 \mu \mathrm{m} ; \mathrm{C}=100 \mu \mathrm{m} ; \mathrm{D}=200 \mu \mathrm{m}$. 


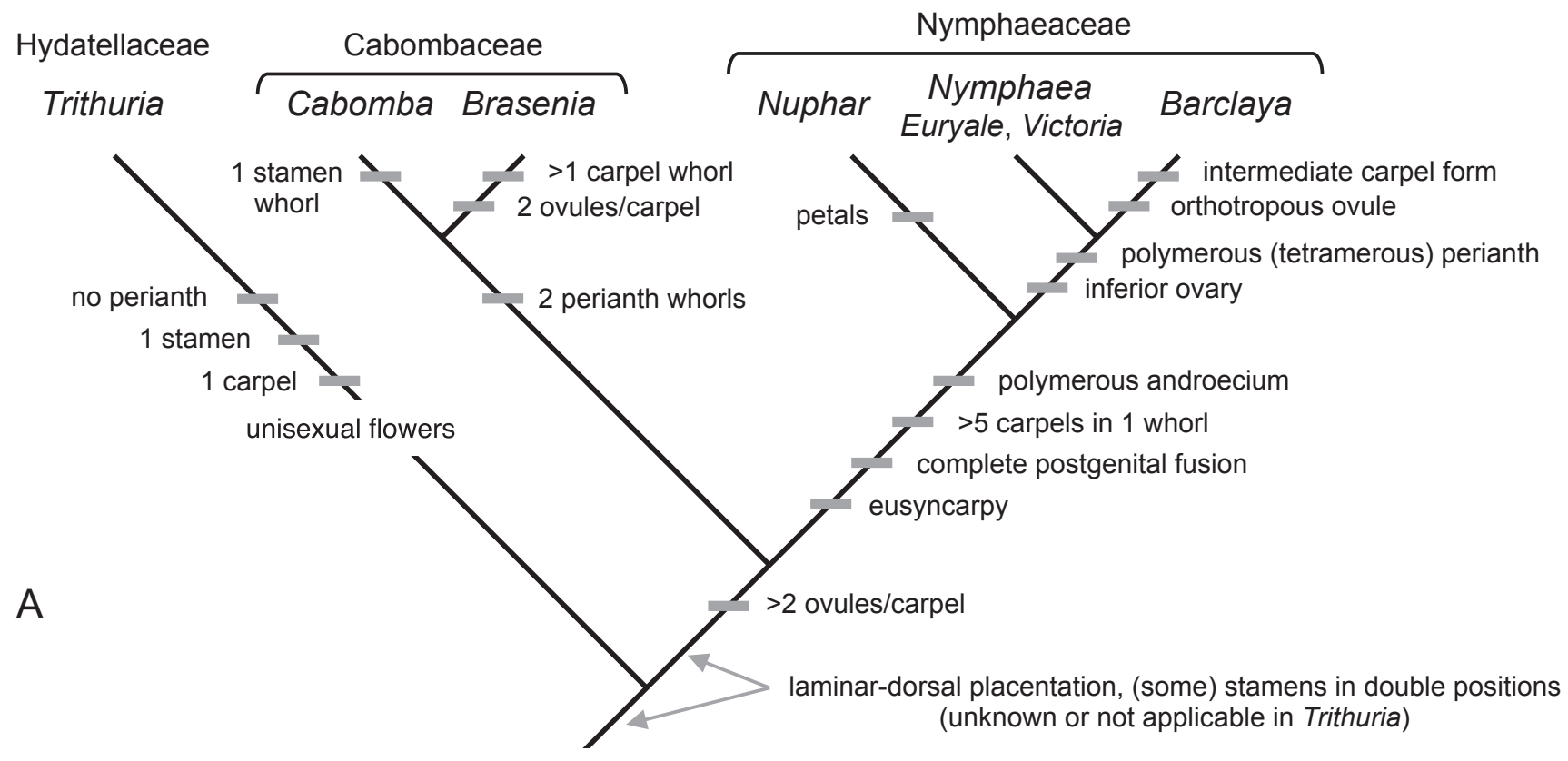

whorled, trimerous perianth \& androecium (equivocal if ancestral or derived; not applicable in Trithuria)

>2 whorls/series of perianth \& androecium; 2-5 carpels in 1 whorl/series, ascidiate, sealed by secretion; 1 anatropous ovule/carpel

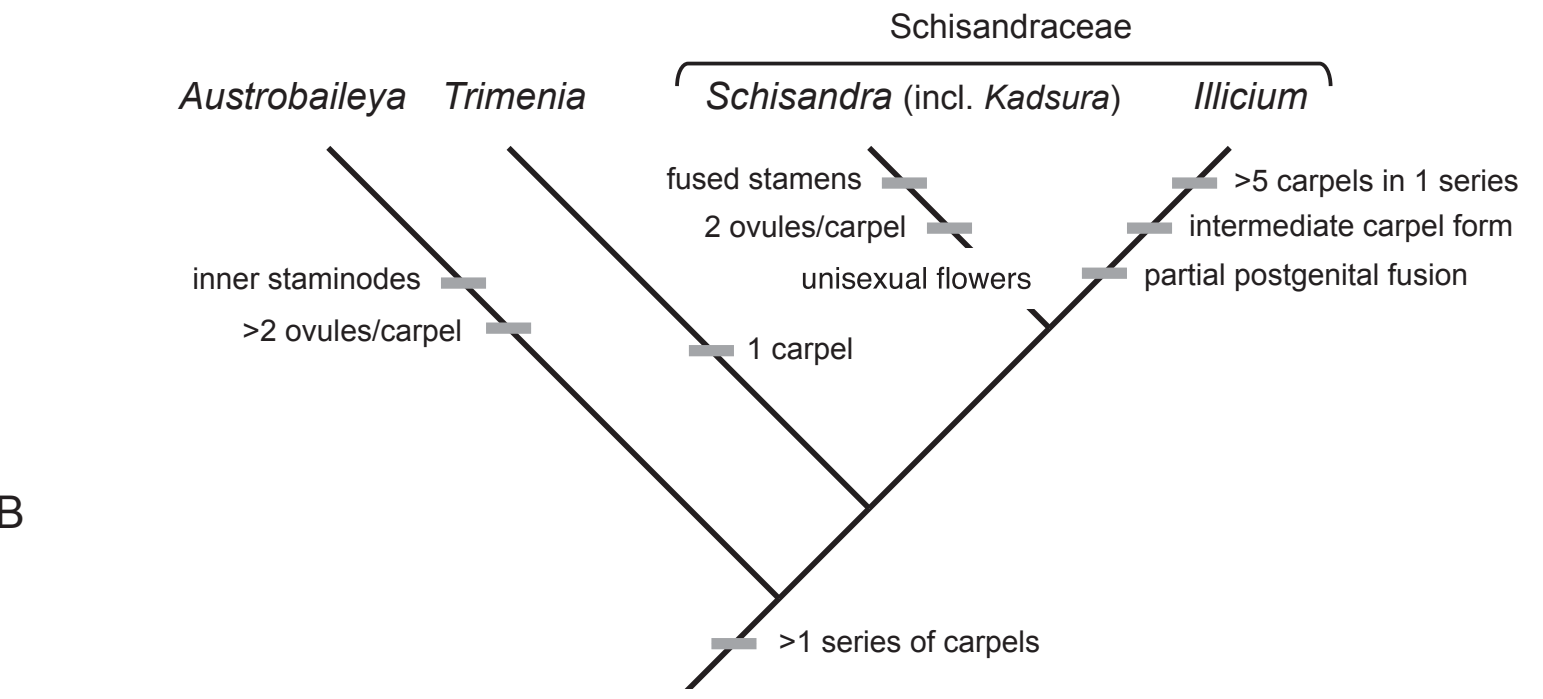

spiral perianth \& androecium (equivocal if ancestral or derived)

>2 whorls/series of perianth \& androecium; 2-5 carpels in 1 whorl/series, ascidiate, sealed by secretion; 1 anatropous ovule/carpel

Fig. 9. Inferred evolution of floral characters discussed in the text in (A) Nymphaeales and (B) Austrobaileyales based on parsimony optimization. Grey bars indicate most parsimonious positions for origin of the derived character states (apomorphies) listed. Character states listed at the base of each tree are those reconstructed for the stem node of the order (note that they are identical for both orders); character states superimposed on branches are inferred to occur on the branch indicated but cannot be characterized as ancestral or derived based on parsimony (i.e., their polarity is equivocal). Data from Doyle \& Endress (2014), analysed using MacClade (Maddison \& Maddison, 2003). 
sized and have a perianth consisting of two trimerous whorls (Fig. 8E). In Cabomba the perianth whorls are simple, but the androecium is arranged in a complex whorl of six stamens (marked with "3" in Fig. 8F). This represents a simple doubling in the androecium, which is therefore hexamerous, but the gynoecium is again trimerous, and the carpels alternate with the three double positions of the stamens (Fig. 8F). In the simple flowers of Cabomba schwartzii Rataj, there are only seven organs in simple dimerous whorls: two outer tepals, two inner tepals, two stamens and one carpel (Rataj, 1977). In Brasenia, doubling of stamens continues in the third androecium whorl (Ito, 1986). Relative to the inferred common ancestor of Cabombaceae and Nymphaeaceae, the perianth was reduced from more than two whorls to two whorls in Cabombaceae, and in Cabomba the androecium was reduced to one whorl with stamens in double positions. Anthesis lasts for two days in both Cabomba, which is insect pollinated, and Brasenia, which is wind pollinated (Schneider \& Jeter, 1982; Osborn \& Schneider, 1988; Taylor \& Williams, 2009; Lima \& al. 2014).

The fully ascidiate carpels contain two to several anatropous ovules, which represents an increase in ovule number if the first Nymphaeales were uniovulate. Interestingly, the ovules are on the dorsal side of the carpel locule rather than the ventral side, which we have treated as the same state as the laminar placentation of Nymphaeaceae. This implies that there was a shift from ventral to laminar/dorsal placentation on the line leading to Cabombaceae and Nymphaeaceae. However, the timing of this shift is equivocal because the state of this character in Hydatellaceae has not been determined (i.e., whether the one ovule is attached to the ventral or the dorsal side of the carpel locule).

Nymphaeaceae. - In Nymphaeaceae, two sets of floral changes can be inferred. The first and most conspicuous is an increase in flower size combined with an increase in floral organ number (up to 44 tepals, 700 stamens and 47 carpels in species of Nymphaea; Wiersema, 1988). The second set includes partial syncarpy, an increase in ovule number, and prominent lateral-laminar diffuse placentation (presumed to be related to the dorsal placentation seen in Cabombaceae), combined with a switch from carpel sealing by secretion to sealing by postgenital fusion. In pollination biology there is a shift from generalized pollination to pollination by large beetles (Cyclocephala Dejean, Scarabaeidae; Prance \& Arias, 1975; Prance \& Anderson, 1977), concomitant with a change from diurnal to nocturnal flowering, which occurs in Victoria and several tropical Nymphaea species. The clades with these extreme specializations are highly nested in the family and therefore relatively young (Yoo \& al., 2005; Borsch \& al., 2008; Löhne \& al., 2008), although fossil evidence for the presence of crown group Nymphaeaceae in the Early Cretaceous (Friis \& al., 2009; Doyle \& Endress, 2014) indicates that diversification of the family was not as recent as inferred by the molecular dating analysis of Yoo \& al. (2005). Another specialization is thermogenicity of the flowers, which plays a role in attraction of beetles. Heat is produced by the so-called carpel appendages (Skubatz \& al., 1990), which are the specialized unifacial styles of the carpels (see above, under "Carpels, angiospermy").
In Nymphaeaceae, Nuphar has three or usually more tepals (Fig. 8G). Nymphaea and other genera have a whorl of four outer tepals, inferred to represent an evolutionary increase in merism, and several complex whorls of additional tepals and of stamens (Fig. 8H). All genera have a whorl of numerous partly united carpels, another derived condition; in addition, the ovary became inferior after the divergence of Nuphar. In Fig. 8H of Nymphaea double positions begin in the third tepal whorl. In Nuphar double positions begin in the second whorl of the inner tepals (the inner tepals have sometimes been called "petals", since they have features like the petals of eudicots). It is important to emphasize that the flowers of all Nymphaeaceae so far investigated have a complex-whorled, not spiral phyllotaxis (Endress, 2001; Schneider \& al., 2003). Thus descriptions of Nymphaeaceae in textbooks and Floras as having spiral parts are erroneous. A longitudinal section through a Nymphaea gynoecium (Fig. 8I) shows the ascidiate shape of the fused carpels and the diffuse laminar position of the numerous pendent ovules on the carpel flanks. Because of the strongly ascidiate shape, the inner spaces of the individual carpels are completely separated from each other, so that there is no centralized pollen tube transmitting tract (intragynoecial compitum) serving all carpels together, as is so common in eudicots and monocots. Instead, a watery stigmatic secretion that collects in the centre of the flower in Nymphaea species (Schmucker, 1932) may act as an extragynoecial compitum (Fig. 8H). Some Nymphaeaceae with especially large flowers (Victoria, Euryale Salisb.) are provided with hard protective spines on the outside of the flowers (and on vegetative parts).

The ovules are anatropous except in Barclaya, which has orthotropous ovules (Schneider, 1978), a clearly derived state in this case. Here the condition is different from that discussed in Amborella. Like other nymphaeaceous genera, Barclaya has large locules with ample space for the ovules (cf. Friis \& al., 2009), and the locule contains mucilage, which mediates the connection between the space of the pollen tube transmitting tract and the micropyle of the ovules for the pollen tubes.

Austrobaileyales. - Floral phyllotaxis is spiral throughout (Endress, 2001). The perianth is more or less caducous, with a well-developed abscission zone at the base of each tepal. By contrast, in the two other lines of the ANITA grade, and in Hedyosmum (the only living genus with a perianth in Chloranthales and Ceratophyllales), the tepals remain attached while senescing (Endress, 2008a). Although this character has not been included in phylogenetic analyses, the caduous state is presumably derived and therefore a synapomorphy of the order. Setting aside the question of whether spiral phyllotaxis is ancestral or derived, the other main floral change on the line to Austrobaileyales was an increase in carpel number. Changes in floral morphology inferred within the order are shown in Fig. 9B.

Austrobaileyaceae. - In Austrobaileyaceae (Austrobaileya), the flowers are bisexual and large (4 $\mathrm{cm}$ across), with numerous organs (Fig. 10A, B; Endress, 1980b, 1983). Given the smaller floral size in most of the outgroups (except Nymphaeaceae, which are inferred from their position to have secondarily large flowers), this large size is presumably an increase. 

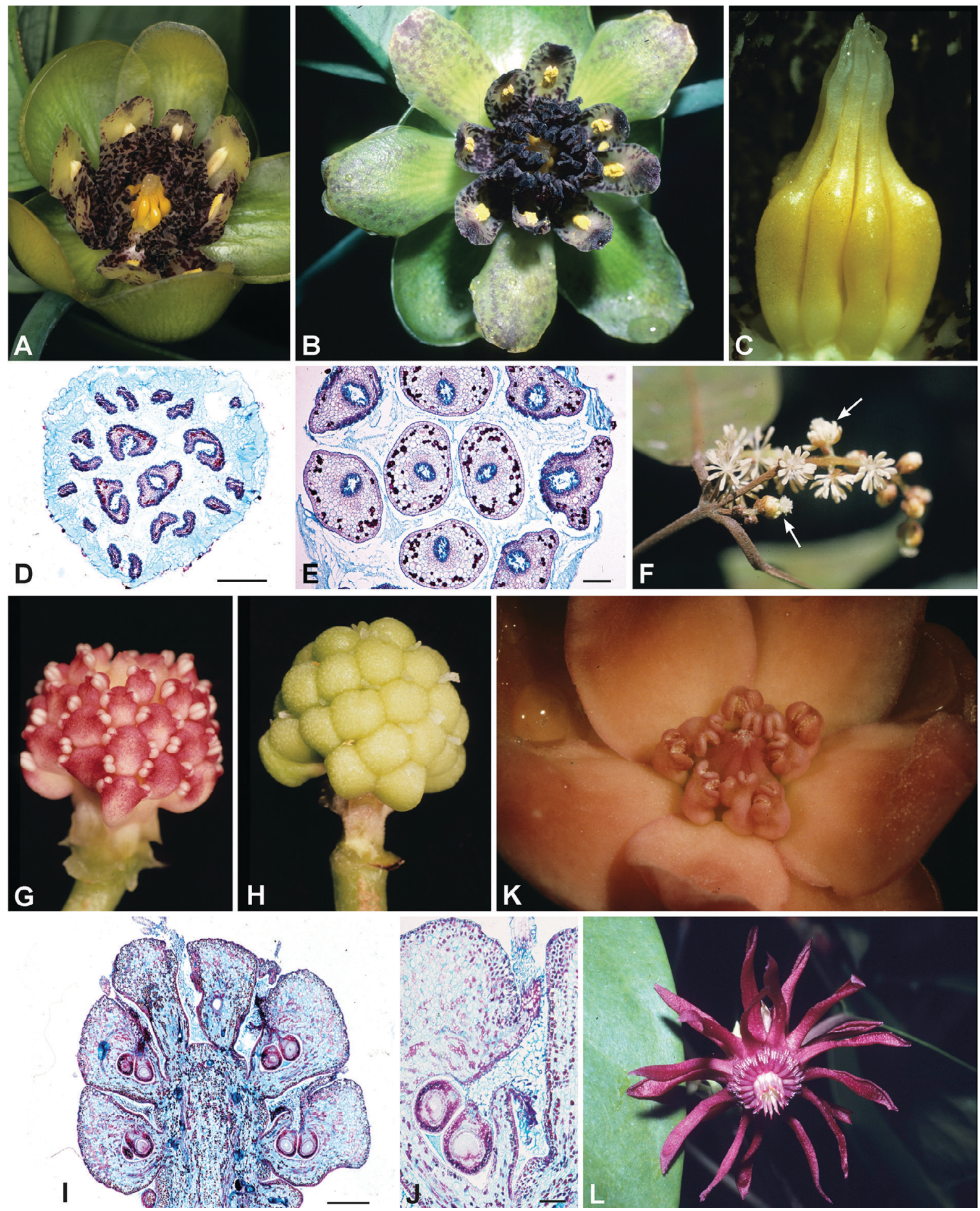

Fig. 10. Austrobaileyales. A-E, Austrobaileyaceae, Austrobaileya scandens: A, flower at female stage of anthesis, anthers still closed, gynoecium exposed; B, flower at male stage of anthesis, anthers open, gynoecium covered by inner staminodes; C, gynoecium with cap of mucilage; D-E, transverse microtome sections of upper part of gynoecium, surrounded with mucilage: $\mathbf{D}$, level of transversally bifid secretory tips of carpels; E, slightly lower in ascidiate zone. F, Trimeniaceae, Trimenia moorei (Oliv.) Philipson; inflorescence with bisexual (arrows) and male flowers. G-L, Schisandraceae: G-J, Kadsura japonica (L.) Dunal (perianth removed in G and H): G, androecium of male flower, anthers still closed; $\mathbf{H}$, gynoecium of female flower; I-J, median longitudinal microtome sections of parts of female flowers: I, gynoecium, note the bulging dorsal carpel parts, which form a thick peripheral zone of the gynoecium, and blue-colored mucilage in the interspaces between the carpels; $\mathbf{J}$, single carpel, note the ascidiate form and the mucilage-filled inner carpel space; $\mathbf{K}$, Illicium lanceolatum A.C.Smith, a species with relatively few floral organs; L, I. floridanum J.Ellis, a species with numerous floral organs. — Magnification bars: D, E, J = $200 \mu \mathrm{m} ; \mathrm{I}=500 \mu \mathrm{m}$. 
Conspicuous features are laminar stamens with elongate thecae in the middle of the ventral side (introrse) and narrow, irregularly longitudinally furrowed inner staminodes (Endress, 1984). The inner staminodes recall those of some Magnoliales and have been discussed together with them (Endress, 1984), but they are evidently convergent with magnoliids and autapomorphic in the ANITA grade (Endress \& Doyle, 2009). Both stamens and staminodes emit a smell of rotten fish. Pollination is by flies. The gynoecium has a cap of mucilage on top of the free carpels (Fig. 10C-E), which forms a kind of extragynoecial compitum; as in Nymphaeales, a normal, intragynoecial compitum is lacking (see above).

Trimeniaceae. - Trimeniaceae (Trimenia Seem.) have small bisexual and male flowers (Endress \& Sampson, 1983; Fig. 10F), with numerous small tepals that are shed early in anthesis. Their most pronounced derived feature is reduction of carpel number to one, a convergence with Hydatellaceae, Chloranthaceae, and Ceratophyllum. The ovule has several meiocytes and may eventually produce several long, slender gametophytes (embryo sacs; Endress \& Sampson, 1983). Bachelier \& Friedman (2011; Friedman \& Bachelier, 2013) found indications of female gametophyte competition, in addition to male gametophyte competition, because the embryo sac tubes behaved in a similar way in a specialized tissue in the long nucellus to pollen tubes in a pollen tube transmitting tract. So far this is unique among the ANITA grade. Perhaps female gametophyte competition could evolve more easily because means of pollen tube competition are less differentiated in these basal angiosperms. This needs broader studies in additional clades. Among magnoliids, a similar situation with several embryo sac tubes occurs in several Laurales, such as Calycanthus L. (Calycanthaceae; Mathur, 1968), Chimonanthus Lindl. (Calycanthaceae; Endress, 1972), Cassytha Mill., Endiandra R.Br. and Ocotea Aubl. (Lauraceae; Endress \& Igersheim, 1997a; Heo \& al., 1998), and Siparuna Aubl. (Siparunaceae; Endress, 1972; Kimoto \& Tobe, 2003).

Schisandraceae. - Schisandraceae as defined by APG III (2009) include both Schisandraceae in the traditional sense, i.e., Schisandra and Kadsura Kaempf. ex Juss., and Illiciaceae, with the single genus Illicium. Kadsura may be nested within Schisandra, but this has not been resolved (Liu \& al., 2006). A conspicuous increase in number of floral organs, especially in the androecium and gynoecium, occurs in part of the family. However, unlike in Nymphaeaceae, the flowers are not especially large. In Schisandra s.l., the flowers are unisexual, or occasionally at least morphologically bisexual (with a few organs of the opposite gender; Saunders, 2000; and P.K. Endress, pers. obs.). Both androecium and gynoecium form compact fleshy bodies with more or less narrow interspaces between the organs (Fig. 10G, H). The carpels are free but the ovaries bulge to the sides and upwards. The dorsal walls form a shield-like structure and the stigmas emerge like snorkels between the almost contiguous carpel flanks. The stamens have broad connectives and are either free or more or less fused below the anthers. At anthesis the system of clefts between the carpels, including the lower portion of the stigmas, is filled with a mucilaginous secretion functioning as an extragynoecial compitum (Fig. 10I, J). Lyew \& al. (2007) described the stigmas as dry because they are covered by a cuticle, but this terminology may be misleading in view of the large quantity of mucilage that is produced and accumulates below the cuticle.

Illicium differs in having bisexual flowers and plicate (not ascidiate) carpels with postgenitally fused ventral slits, although we have scored carpel form as intermediate because the single ovule is strictly median, as in other basal angiosperms where the ovule is borne on the cross-zone of a peltate carpel (Doyle \& Endress, 2000; Endress \& Doyle, 2009; Fig. 4). The carpels and the stamens are displayed in multiparted rings (Fig. 10K, L). This gives the superficial impression of a whorled organ arrangement, but in reality the floral phyllotaxis is spiral, as in all other Austrobaileyales studied to date. The unusual carpel form combined with postgenital intracarpellary fusion is related to the opening of the carpel in fruit and the explosive expulsion of the single seed (Romanov \& al., 2013).

Chloranthales (Chloranthaceae). - In the small flowers of Chloranthaceae, the fertile parts are usually reduced to a single stamen and/or a single carpel containing one pendent orthotropous ovule, and except in the female flowers of Hedyosmum there is no perianth (Endress, 1971, 1987b). Flowers are unisexual in Hedyosmum and Ascarina J.R.Forst. \& G.Forst. It is possible that the seemingly bisexual flowers of Sarcandra Gardner and Chloranthus Sw. are actually pseudanthia composed of a male and a female flower, and thus are also unisexual (Moore, 1977; Doyle \& al., 2003; Omori, 2003; Doyle \& Endress, 2014). Although some earlier authors suggested that the simple flowers of Chloranthaceae provided an alternative prototype for the angiosperm flower (e.g., Meeuse, 1972; Burger, 1977), the current phylogenetic framework clearly implies that they were derived by reduction. An intermediate stage in this reduction is illustrated by an Early Cretaceous flower (Canrightia: Friis $\&$ Pedersen, 2011) that is bisexual, with one whorl of reduced tepals, a few stamens, and a gynoecium of a few fused carpels; its significance as an intermediate is confirmed by phylogenetic analyses (Friis \& Pedersen, 2011; Doyle \& Endress, 2014) that placed it on the stem lineage of Chloranthaceae (with or without Ceratophyllum). Scenarios for floral evolution within Chloranthaceae based on phylogenetic analysis were proposed by Doyle $\&$ al. (2003) and refined with the addition of more recently described fossil taxa by Doyle \& Endress (2014).

In Sarcandra, each flower consists of a single stamen and a single carpel and is borne in the axil of a bract (Fig. 11D). In Chloranthus the flower is similar, but the androecium is a three-lobed unit that forms a broad scale, partly covering the carpel (Fig. 11G, H). This three-lobed androecium is unique. It serves to protect the gynoecium during development, and at least in some species it probably also acts as a shelter for pollinating thrips (for thrips pollination in Chloranthus, see Ma \& al., 1997; Wang \& al., 1998; Luo \& Li, 1999).

The pathway of morphological evolution of this "tripartite androecium" is unsettled. Either it evolved by fusion of three original stamens with a one-sided (monosymmetric) position, or it evolved by trilobation of an ancestrally simple stamen and fractionation of each theca into two parts (Endress, 1987b; Doyle \& al., 2003). The first scenario may be suggested by 

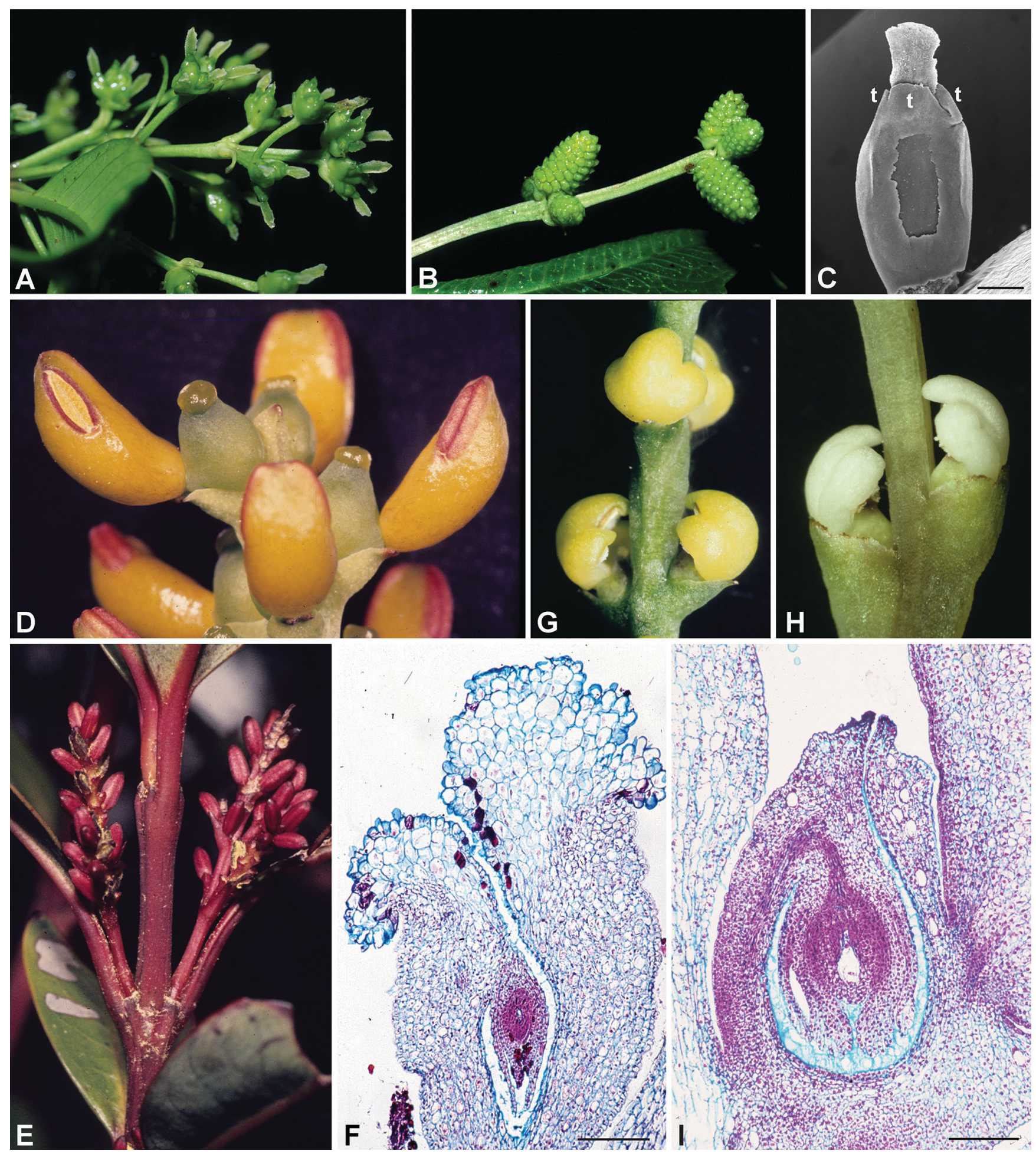

Fig. 11. Chloranthaceae. A-C, Hedyosmum: A, H. costaricense C.E.Wood ex W.C.Burger, female inflorescence, anthetic; B, H. costaricense, male inflorescence, preanthetic; C, Hedyosmum mexicanum C.Cordem., female flower, preanthetic ( $\mathrm{t}=$ tepals). D, Sarcandra chloranthoides Gardner, tip of inflorescence with several bisexual flowers. E-F, Ascarina rubricaulis Solms: E, male inflorescences; $\mathbf{F}$, median longitudinal microtome section of anthetic carpel, note large stigmatic surface and unfused, mucilage-filled inner space of carpel. G-I, Chloranthus: G, C. spicatus (Thunb.) Makino, part of inflorescence with several flowers, note the three-lobed scales of the androecium; H, C. serratus (Thunb.) Roem. $\&$ Schult., ditto, note the lateral fusion of the subtending bracts with the axis, forming a protective sheath for the young perianthless flowers; I, C. erectus, median longitudinal microtome section of anthetic carpel, note small stigmatic surface and unfused, mucilage-filled inner space of carpel. - Magnification bars: $\mathrm{C}=500 \mu \mathrm{m} ; \mathrm{F}, \mathrm{I}=200 \mu \mathrm{m}$. 
Late Cretaceous flowers (Chloranthistemon Crane \& al.) in which the three lobes are free down to the base (Eklund \& al., 1997, 2004) and an Early Cretaceous fossil (Canrightiopsis Friis \& al.) with three distinct stamens adnate to a carpel (Friis \& al., 2015). The second scenario may be supported by variations observed in extant species. In Sarcandra, the sister genus of Chloranthus with simple stamens, exceptional stamens with three tips may occur (P.K. Endress, pers. obs.), which could represent incipient lobation of this kind. In addition, Maekawa (1970) observed a diversity of abnormal stamen forms in Chloranthus japonicus Siebold, among them simple, unlobed stamens with two normal thecae.

Floral protection during development of the perianthless flowers in Chloranthus is thus two-fold. At first the flower is covered by the subtending bract, which is laterally fused with the stem and thus forms a tight container around the flower (Fig. 11H). And later the massive concave androecial scale forms a partial protection around the gynoecium (Fig. 11G, H; von Balthazar \& Endress, 1999). In Sarcandra, the protective mechanism is similar, except that the androecium, being a single stamen, is less broad.

Hedyosmum is the only extant genus in Chloranthaceae that has a perianth, which consists of three small, basally fused tepals that are adnate to the carpel (Fig. 11A, C); the male flowers have no perianth. A second and weird specialization in female Hedyosmum flowers is "windows" on the outer flanks of the flower at the level of the inferior ovary. They are functional in the fruit when the window "frames" (Endress, 1971) become fleshy and colored, together with the bracts in the putatively derived subgenus Tafalla Solms (Todzia, 1988; Eklund \& al., 2004). Potential functions at anthesis are unknown. The development of these windows has been misinterpreted by various authors (most recently Doria \& al., 2012; see Doyle \& Endress, 2014). They originate as three shallow depressions on the outer surface of the hypanthium below the three tepals. The rims of the depressions become more accentuated and later look like perforated diaphragms by passive growth of the region behind them following the increase in size of the flower (Endress, 1971). The male structures of Hedyosmum have been interpreted as multistaminate flowers (Leroy, 1983), but comparison with other members of the family indicates that they are more likely spikes of flowers that each consist of a single stamen (Endress, 1987b). Subtending floral bracts are lacking, but the tightly arranged stamens (unistaminate flowers) are cuneate and in some species protect each other in bud with extended apices (Fig. 11B; Endress, 2008b). It is possible that the floral subtending bract has not completely disappeared but is amalgamated with the stamen as the projecting apex. However, detailed studies are needed to test this.

Ceratophyllales (Ceratophyllaceae, Ceratophyllum). Ceratophyllaceae are unique in lacking roots, living completely submerged and floating in standing water, and even being pollinated and dispersed under water. They are highly reduced morphologically and anatomically. We interpret the flowers as consisting of a single stamen or a single carpel, with no perianth, as in Ascarina in the Chloranthaceae. Earlier interpretations of the flowers as having a perianth (Caruel, 1876; Strasburger, 1902; Jones, 1931; Sehgal \& Ram, 1981) and of the male flowers as consisting of groups of numerous stamens (Caruel, 1876; Strasburger, 1902; Jones, 1931; Sehgal \& Ram, 1981; Endress, 1994; Iwamoto \& al., 2003) are probably incorrect (Endress, 2004).

The hypothesis that Ceratophyllum has a perianth is based on the presence of a series of bract-like leaves surrounding each group of stamens or single carpel; these leaves are basally fused in the male structures. The vegetative leaves are also disposed in whorls but are larger and dissected and not fused. However, a strong argument against the perianth hypothesis is the presence of lateral shoots (flowers) in the axils of the surrounding organs, which are therefore best interpreted as bracts, rather than tepals (Aboy, 1936).

The hypothesis that each stamen represents a male flower is supported by two oddities. First, at intermediate stages of development of a stamen group the stamens are at extremely different developmental stages, showing a strong delay in the development of the inner stamens (Fig. 12A-C; Endress, 1994; Iwamoto \& al., 2003). Although some delay in stamen development may occur in multistaminate flowers, we are not aware of any such flowers that show the degree of unequal maturation that is observed in Ceratophyllum, but it is common in inflorescences (see, e.g., discussion on Asteraceae by Burtt, 1961). Second, the phyllotaxis and merism of these stamen groups are extremely variable, which also fits better with an inflorescence than with a flower. Endress (1994) found whorls of three or four stamens, as well as spiral Fibonacci patterns and spiral Lucas patterns. Iwamoto \& al. (2003) reported similar variation, but they argued that it reflected a shift in phyllotaxis during development of the stamen group; however, they apparently confused a spiral sequence of development (spiral order of initiation of organs within a whorl, while each successive whorl still alternates with the last, which is the defining feature of whorled phyllotaxis: Endress \& Doyle, 2007) with spiral phyllotaxis. The whole structure is comparable to the male inflorescence of Hedyosmum, which is a spike of flowers consisting of one stamen that are not subtended by bracts. It might be presumed that the simple flowers in Ceratophyllum were a result of reduction in an aquatic habitat, but if Ceratophyllum and Chloranthaceae are sister groups, it is most parsimonious to assume that the reduction of their flowers had already occurred in their common ancestor, which was presumably terrestrial.

The interpretation of the female flower has also been controversial (Strasburger, 1902; Endress, 1994; Iwamoto \& al., 2003; Shamrov, 2009). Endress (1994) and Iwamoto \& al. (2003) interpreted the gynoecium as a single carpel, with an unusual ventral style-like extension and the ovule attached to the ventral side, but Shamrov (2009) interpreted it as composed of two united carpels, one of them sterile, with the ovule on the dorsal side (i.e., midline) of the fertile carpel. Both views are consistent with the observation that both sides of the carpel are equally tall at an early developmental stage but the side with the ovule subsequently elongates (Shamrov, 1983, 2009; Endress, 1994; Iwamoto \& al., 2003; this paper, Fig. 12D). However, a combination of pseudomonomery and dorsal placenta seems 
rather unlikely. As noted in the discussion of the style, Iwamoto $\&$ al. (2003) identified the side with the style-like extension (and the ovule) as ventral, because the side opposite to it bears a secretory tip (active at early developmental stages) similar to one found at the apex of other organs (as also figured in Strasburger, 1902). However, if the gland is not considered to be a reliable landmark, the side that is longer at anthesis might be interpreted as dorsal, which is the case in most carpels, and the ovule is therefore attached to the dorsal side of the locule, as in Cabombaceae.

Ceratophyllum is further unique in basal angiosperms in having orthotropous unitegmic ovules (e.g., Shamrov, 1983, 1997; Igersheim \& Endress, 1998; Fig. 7E). If Chloranthaceae and Ceratophyllum are sister groups, their orthotropous ovules are presumably a synapomorphy uniting them, but the unitegmic condition in Ceratophyllum is an autapomorphy.

\section{- CONCLUSIONS}

Because Amborella, Nymphaeales, and Austrobaileyales (the ANITA groups) form a basal grade of lines that diverge below the vast majority of living angiosperms (the mesangiosperm clade), they offer a unique opportunity to reconstruct ancestral states in angiosperms and their early modifications. However, some characters vary too much among these taxa to identify ancestral states with parsimony.
In the ANITA grade, floral phyllotaxis is either whorled (specifically complex whorled, with double organ positions in at least one whorl) in Nymphaeales or spiral in Amborella and Austrobaileyales. The ancestral state is unresolved with parsimony analysis, but if it was whorled, the outer whorls were trimerous. These observations suggest that whorled and spiral phyllotaxis can switch easily in such flowers with a low degree of synorganization. Both the complex-whorled and spiral patterns are more favourable for an increase in organ number than the simple-whorled pattern.

Carpels are largely ascidiate and carpel closure (angiospermy) is by secretion only in the basal grade, except for two advanced lines, in which the carpel flanks fuse postgenitally: Nymphaeaceae (Nymphaeales), in conjunction with extreme enlargement of the flowers and syncarpy, and Illicium (Austrobaileyales), which has largely plicate carpels, in conjunction with explosive seed expulsion. Carpels with a single median pendent ovule occur in representatives of all three orders of the basal grade, as well as in many Early Cretaceous fossils, and this condition is probably plesiomorphic. Carpel closure is either by a short transverse slit or by a short longitudinal slit, different conditions than in the majority of angiosperms. A style, if present at all, is short and is not plicate but ascidiate, unifacial, or flat. Concomitantly, the pollen tube transmitting tract is also short. These carpel and ovule features are notably also present in Chloranthaceae and Ceratophyllaceae, which have an unresolved phylogenetic position but may form an
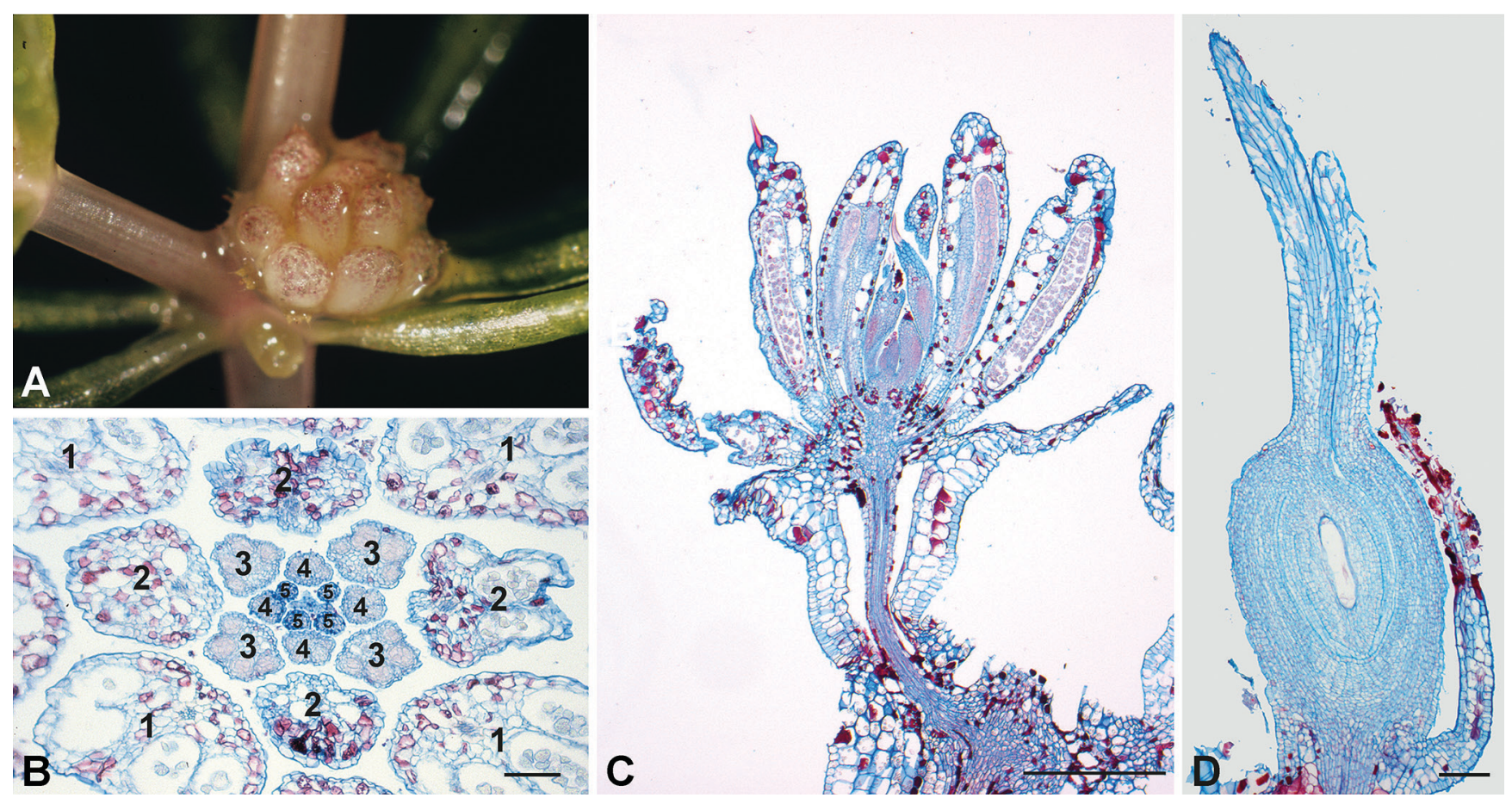

Fig. 12. Ceratophyllaceae, Ceratophyllum demersum. A-C, male inflorescences: A, inflorescence in situ; B, transverse microtome section of inflorescence, note 4-merous whorls of male flowers (single stamens), organs of several whorls are numbered, note the steep centripetal gradient of delay in development; $\mathbf{C}$, longitudinal median microtome section of inflorescence, note the steep developmental gradient toward the centre. D, female flower, median longitudinal microtome section, note position of the ovule on the side of the longer carpel wall. - Magnification bars: $\mathrm{B}, \mathrm{D}=100 \mu \mathrm{m} ; \mathrm{C}=500 \mu \mathrm{m}$. 
additional branch immediately above the basal grade, as the sister group of the remaining mesangiosperms (the vast majority of living angiosperms, consisting of the magnoliid, eudicot, and monocot clades).

Flowers in the basal grade are either bisexual or unisexual. However, in many cases, functionally unisexual flowers are morphologically bisexual, which suggests the ancestral state is more likely bisexual than unisexual. It is still ambiguous whether ancestral embryo sacs underwent only two rounds of cell division and thus were 4-nucleate, as in Nymphaeales and Austrobaileyales, or whether the 4-nucleate condition was an early apomorphy of these orders that did not exist on the lines leading to other clades of angiosperms. Likelihood-based methods for ancestral state reconstruction could be informative in such cases where parsimony methods are ambiguous. Some questions concerning character evolution could be clarified by resolution of persisting phylogenetic ambiguities, such as the relationships of Chloranthaceae, Ceratophyllum, and the three other mesangiosperm lines, perhaps by analysis of sequences of numerous nuclear genes obtained from next-generation sequencing.

\section{ACKNOWLEDGEMENTS}

We thank Rosemarie Siegrist for microtome sections, Urs Jauch and Doris Metzger for help with the SEM, and Alex Bernhard for graphical work. Wilhelm Barthlott is thanked for kindly providing the photo for Fig. 10A. Toby Pennington, Gerhard Prenner, and an anonymous reviewer provided helpful suggestions for clarification of phylogenetic and morphological issues and other improvements in the manuscript. Michael Frohlich shared personal insights on the evolution of unisexual flowers in Amborella.

\section{- LITERATURE CITED}

Aboy, H.E. 1936. A study of the anatomy and morphology of Ceratophyllum demersum. Unpublished M.Sc. thesis. Cornell University, Ithaca, New York, U.S.A.

Antonov, A.S., Troitsky, A.V., Samigullin, T.K., Bobrova, V.K., Valiejo-Roman, K.M. \& Martin, W. 2000. Early events in the evolution of angiosperms deduced from cp rDNA ITS 2-4 sequence comparisons. Pp. 210-214 in: Liu, Y.-H., Fan, H.-M., Chen, Z.-Y., Wu, Q.-G. \& Zeng, Q.-W. (eds.), Proceedings of the International Symposium on the Family Magnoliaceae. Beijing: Science Press.

APG III 2009. An update of the Angiosperm Phylogeny Group classification for the orders and families of flowering plants: APG III. Bot. J. Linn. Soc. 161: 105-121. http://dx.doi.org/10.1111/j.1095-8339.2009.00996.x

Bachelier, J.B. \& Friedman, W.E. 2011. Female gamete competition in an ancient angiosperm lineage. Proc. Natl. Acad. Sci. U.S.A. 108: 12360-12365. http://dx.doi.org/10.1073/pnas.1104697108

Barkman, T.J., Chenery, G., McNeal, J.R., Lyons-Weller, J., Ellisens, W.J., Moore, G., Wolfe, A.D. \& dePamphilis, C.W. 2000. Independent and combined analyses of sequences from all three genomic compartments converge on the root of flowering plant phylogeny. Proc. Natl. Acad. Sci. U.S.A. 97: 13166-13171. http://dx.doi.org/10.1073/pnas.220427497
Bateman, R.M., Hilton, J. \& Rudall, P.J. 2006. Morphological and molecular phylogenetic context of the angiosperms: Contrasting the 'top-down' and 'bottom-up' approaches used to infer the likely characteristics of the first flowers. J. Exp. Bot. 57: 3471-3503. http://dx.doi.org/10.1093/jxb/erl128

Batygina, T.B., Shamrov, I.I. \& Kolesova, G.E. 1982. Èmbriologiâ nimfejnyh i lotosovyh. II. Razvitie ženskyh èmbrional'nyh struktur [Embryology of the Nymphaeales and Nelumbonales. II. The development of the female embryonic structures.] Bot. Zhurn. (Moscow \& Leningrad) 67: 1179-1195.

Bernhardt, P. \& Thien, L.B. 1987. Self-isolation and insect pollination in the primitive angiosperms: New evaluations of older hypotheses. Pl. Syst. Evol. 156: 159-176. http://dx.doi.org/10.1007/BF00936071

Bobrov, A.V.F.C., Endress, P.K., Melikian, A.P., Romanov, M.S., Sorokin, A.N. \& Beyerano, A.P. 2005. Fruit structure of Amborella trichopoda (Amborellaceae). Bot. J. Linn. Soc. 148: 265-274. http://dx.doi.org/10.1111/j.1095-8339.2005.00422.x

Borsch, T., Löhne, C. \& Wiersema, J. 2008. Phylogeny and evolutionary patterns in Nymphaeales: Integrating genes, genomes and morphology. Taxon 57: 1052-1081. http://www.jstor.org/stable/27756765

Burger, W.C. 1977. The Piperales and the monocots: Alternate hypotheses for the origin of monocotyledonous flowers. Bot. Rev. (Lancaster) 43: 345-393. http://dx.doi.org/10.1007/BF02860716

Burtt, B.L. 1961. Compositae and the study of functional evolution. Trans. Bot. Soc. Edinburgh 39: 216-232. http://dx.doi.org/10.1080/13594866109441703

Buzgo, M., Soltis, P.S. \& Soltis, D.E. 2004. Floral developmental morphology of Amborella trichopoda (Amborellaceae). Int. J. Pl. Sci. 165: 925-947. http://dx.doi.org/10.1086/424024

Cantino, P.D., Doyle, J.A., Graham, S.W., Judd, W.S., Olmstead, R.G., Soltis, D.E., Soltis, P.S. \& Donoghue, M.J. 2007. Towards a phylogenetic nomenclature of Tracheophyta. Taxon 56: 822-846. http://dx.doi.org/10.2307/25065865

Caruel, T. 1876. Sui fiori di Ceratophyllum. Nuovo Giorn. Bot. Ital. 8: 28-33.

Chase, M.W., Soltis, D.E., Olmstead, R.G., Morgan, D., Les, D.H., Mishler, B.D., Duvall, M.R., Price, R.A., Hills, H.G., Qiu, Y.-L., Kron, K.A., Rettig, J.H., Conti, E., Palmer, J.H., Manhart, J.R., Sytsma, K.J., Michaels, H.J., Kress, W.J., Karol, K.G., Clark, W.D., Hedrén, M., Gaut, B.S., Jansen, R.K., Kim, K.-J., Wimpee, C.F., Smith, J.F., Furnier, G.R., Strauss, S.H., Xiang, Q.-Y., Plunkett, G.M., Soltis, P.S., Swensen, S.M., Williams, S.E., Gadek, P.A., Quinn, C.J., Eguiarte, L.E., Golenberg, E., Learn, G.H., Jr., Graham, S.W., Barrett, S.C.H., Dayanandan, S. \& Albert, V.A. 1993. Phylogenetics of seed plants: An analysis of nucleotide sequences from the plastid gene $r b c L$. Ann. Missouri Bot. Gard. 80: 528-580. http://dx.doi.org/10.2307/2399846

Crisp, M.D. \& Cook, L.G. 2005. Do early branching lineages signify ancestral traits? Trends Ecol. Evol. 20: 122-128. http://dx.doi.org/10.1016/j.tree.2004.11.010

Davis, C.C., Endress, P.K. \& Baum, D.A. 2008. The evolution of floral gigantism. Curr. Opin. Pl. Biol. 11: 49-57. http://dx.doi.org/10.1016/j.pbi.2007.11.003

De Klercker, J.-E.-F. 1885. Sur l'anatomie et le développement de Ceratophyllum. Bih. Kongl. Svenska Vetensk.-Akad. Handl. 9(10): 1-23.

Doria, M.G., Pabón-Mora, N. \& González, F. 2012. Reassessing inflorescence and floral morphology and development in Hedyosmum (Chloranthaceae). Int. J. Pl. Sci. 173: 735-750. http://dx.doi.org/10.1086/666662

Doyle, J.A. 2012. Molecular and fossil evidence on the origin of angiosperms. Annual Rev. Earth Planet. Sci. 40: 301-326. http://dx.doi.org/10.1146/annurev-earth-042711-105313

Doyle, J.A. \& Endress, P.K. 2000. Morphological phylogenetic analysis of basal angiosperms: Comparison and combination with molecular data. Int. J. Pl. Sci. 161(Suppl.): S121-S153. http://dx.doi.org/10.1086/317578 
Doyle, J.A. \& Endress, P.K. 2011. Tracing the evolutionary diversification of the flower in basal angiosperms. Pp. 88-119 in: Wanntorp, L. \& Ronse De Craene, L.P. (eds.), Flowers on the tree of life. Cambridge: Cambridge University Press.

Doyle, J.A. \& Endress, P.K. 2010. Integrating early Cretaceous fossils into the phylogeny of living angiosperms: Magnoliidae and eudicots. J. Syst. Evol. 48: 1-35. http://dx.doi.org/10.1111/j.1759-6831.2009.00058.x

Doyle, J.A. \& Endress, P.K. 2014. Integrating Early Cretaceous fossils into the phylogeny of living angiosperms: ANITA lines and relatives of Chloranthaceae. Int. J. Pl. Sci. 175: 555-600. http://dx.doi.org/10.1086/675935

Doyle, J.A., Eklund, H. \& Herendeen, P.S. 2003. Floral evolution in Chloranthaceae: Implications of a morphological phylogenetic analysis. Int. J. Pl. Sci. 164(Suppl.): S365-S382. http://dx.doi.org/10.1086/377064

Drew, B.T., Ruhfel, B.R., Smith, S.A., Moore, M.J., Briggs, B.G., Gitzendanner, M.A., Soltis, P.S. \& Soltis, D.E. 2014. Another look at the root of the angiosperms reveals a familiar tale. Syst. Biol. 63: 368-382. http://dx.doi.org/10.1093/sysbio/syt108

Duvall, M.R., Mathews, S., Mohammad, N. \& Russell, T. 2006. Placing the monocots: Conflicting signal from trigenomic analyses. Aliso 22: 79-90.

Duvall, M.R., Robinson, J.W., Mattson, J.G. \& Moore, A. 2008. Phylogenetic analyses of two mitochondrial metabolic genes sampled in parallel from angiosperms find fundamental interlocus incongruence. Amer. J. Bot. 95: 871-884. http://dx.doi.org/10.3732/ajb.2007310

Edwards, J.G. 1920. Flower and seed of Hedyosmum nutans. Bot. Gaz. 70: 409-424. http://dx.doi.org/10.1086/332774

Eklund, H., Friis, E.M. \& Pedersen, K.R. 1997. Chloranthaceous floral structures from the Late Cretaceous of Sweden. Pl. Syst. Evol. 207: 13-42. http://dx.doi.org/10.1007/BF00985207

Eklund, H., Doyle, J.A. \& Herendeen, P.S. 2004. Morphological phylogenetic analysis of living and fossil Chloranthaceae. Int. J. Pl. Sci. 165: 107-151. http://dx.doi.org/10.1086/380987

Endress, P.K. 1971. Bau der weiblichen Blüten von Hedyosmum mexicanum Cordemoy (Chloranthaceae). Bot. Jahrb. Syst. 91: 39-60.

Endress, P.K. 1972. Zur vergleichenden Entwicklungsmorphologie, Embryologie und Systematik bei Laurales. Bot. Jahrb. Syst. 92: 331-428.

Endress, P.K. 1980a. Ontogeny, function and evolution of extreme floral construction in Monimiaceae. Pl. Syst. Evol. 134: 79-120. http://dx.doi.org/10.1007/BF00985032

Endress, P.K. 1980b. The reproductive structures and systematic position of the Austrobaileyaceae. Bot. Jahrb. Syst. 101: 393-433.

Endress, P.K. 1983. The early floral development of Austrobaileya. Bot. Jahrb. Syst. 103: 481-497.

Endress, P.K. 1984. The role of inner staminodes in the floral display of some relic Magnoliales. Pl. Syst. Evol. 146: 269-282. http://dx.doi.org/10.1007/BF00989551

Endress, P.K. 1986. Reproductive structures and phylogenetic significance of extant primitive angiosperms. Pl. Syst. Evol. 152: 1-28. http://dx.doi.org/10.1007/BF00985348

Endress, P.K. 1987a. Floral phyllotaxis and floral evolution. Bot. Jahrb. Syst. 108: 417-438.

Endress, P.K. 1987b. The Chloranthaceae: Reproductive structures and phylogenetic position. Bot. Jahrb. Syst. 109: 153-226.

Endress, P.K. 1994. Evolutionary aspects of the floral structure in Ceratophyllum. Pl. Syst. Evol., Suppl. 8: 175-183. http://dx.doi.org/10.1007/978-3-7091-6910-0_10

Endress, P.K. 1996. Evolutionary aspects of fruits in basal flowering plants. Norske Vidensk.-Akad., Mat.-Naturvidensk. Kl., Avh. 18: 21-32.

Endress, P.K. 2001. The flowers in extant basal angiosperms and inferences on ancestral flowers. Int. J. Pl. Sci. 162: 1111-1140. http://dx.doi.org/10.1086/321919
Endress, P.K. 2004. Structure and relationships of basal relictual angiosperms. Austral. Syst. Bot. 17: 343-366. http://dx.doi.org/10.1071/SB04004

Endress, P.K. 2005. Carpels of Brasenia (Cabombaceae) are completely ascidiate despite a long stigmatic crest. Ann. Bot. (Oxford) 96: 209-215. http://dx.doi.org/10.1093/aob/mcil74

Endress, P.K. 2006. Angiosperm floral evolution: Morphological developmental framework. Advances Bot. Res. 44: 1-61. http://dx.doi.org/10.1016/S0065-2296(06)44001-5

Endress, P.K. 2008a. Perianth biology in the basal grade of extant angiosperms. Int. J. Pl. Sci. 169: 844-862. http://dx.doi.org/10.1086/589691

Endress, P.K. 2008b. The whole and the parts: Relationships between floral architecture and floral organ shape, and their repercussions on the interpretation of fragmentary floral fossils. Ann. Missouri Bot. Gard. 95: 101-120. http://dx.doi.org/10.3417/2006190

Endress, P.K. 2010. The evolution of floral biology in basal angiosperms. Philos. Trans., Ser. B 365: 411-421. http://dx.doi.org/10.1098/rstb.2009.0228

Endress, P.K. 2011. Angiosperm ovules: Diversity, development, evolution. Ann. Bot. (Oxford) 107: 1465-1489. http://dx.doi.org/10.1093/aob/mcrl20

Endress, P.K. 2015. Patterns of angiospermy development before carpel sealing across living angiosperms: Diversity, and morphological and systematic aspects. Bot. J. Linn. Soc. 178: 556-591. http://dx.doi.org/10.1111/boj.12294

Endress, P.K. \& Doyle, J.A. 2007. Floral phyllotaxis in basal angiosperms - Development and evolution. Curr. Opin. Pl. Biol. 10: 52-57. http://dx.doi.org/10.1016/j.pbi.2006.11.007

Endress, P.K. \& Doyle, J.A. 2009. Reconstructing the ancestral flower and its initial specializations. Amer. J. Bot. 96: 22-66. http://dx.doi.org/10.3732/ajb.0800047

Endress, P.K. \& Igersheim, A. 1997a. Gynoecium diversity and systematics in the Laurales. Bot. J. Linn. Soc. 125: 93-168. http://dx.doi.org/10.1111/j.1095-8339.1997.tb02250.x

Endress, P.K. \& Igersheim, A. 1997b. Patterns of angiospermy in basal angiosperms. Amer. J. Bot. 84(6, Abstracts): 190.

Endress, P.K. \& Igersheim, A. 2000a. Gynoecium structure and evolution in basal angiosperms. Int. J. Pl. Sci. 161(Suppl.): S211-S223. http://dx.doi.org/10.1086/317572

Endress, P.K. \& Igersheim, A. 2000b. The reproductive structures of the basal angiosperm Amborella trichopoda (Amborellaceae). Int. J. Pl. Sci. 161(Suppl.): S237-S248. http://dx.doi.org/10.1086/317572

Endress, P.K. \& Sampson, F.B. 1983. Floral structure and relationships of the Trimeniaceae (Laurales). J. Arnold Arbor. 64: 447-473.

Friedman, W.E. 2006. Embryological evidence for developmental lability during early angiosperm evolution. Nature 441: 337-340. http://dx.doi.org/10.1038/nature04690

Friedman, W.E. \& Bachelier, J.B. 2013. Seed development in Trimenia (Trimeniaceae) and its bearing on the evolution of embryonourishing strategies in early flowering plant lineages. Amer. J. Bot. 100: 906-915. http://dx.doi.org/10.3732/ajb.1200632

Friedman, W.E. \& Ryerson, K.C. 2009. Reconstructing the ancestral female gametophyte of angiosperms: Insights from Amborella and other ancient lineages of flowering plants. Amer. J. Bot. 96: 129-143. http://dx.doi.org/10.3732/ajb.0800311

Friedman, W.E. \& Williams, J.H. 2003. Modularity of the angiosperm female gametophyte and its bearing on the early evolution of endosperm in flowering plants. Evolution 57: 216-230. http://dx.doi.org/10.1111/j.0014-3820.2003.tb00257.x

Friedman, W.E. \& Williams, J.H. 2004. Developmental evolution of the sexual process in ancient flowering plant lineages. Pl. Cell 16: S1-S15. http://dx.doi.org/10.1105/tpc.017277

Friedman, W.E., Gallup, W.N. \& Williams, J.H. 2003. Female gametopyhte development in Kadsura: Implications for Schisandraceae, 
Austrobaileyales, and the early evolution of flowering plants. Int. J. Pl. Sci. 164: S293-S305. http://dx.doi.org/10.1086/376877

Friis, E.M. \& Pedersen, K.R. 2011. Canrightia resinifera gen. et sp. nov., a new extinct angiosperm with Retimonocolpites-type pollen from the Early Cretaceous of Portugal: Missing link in the eumagnoliid tree? Grana 50: 3-29.

http://dx.doi.org/10.1080/00173134.2011.559728

Friis, E.M., Pedersen, K.R., von Balthazar, M., Grimm, G.W. \& Crane, P.R. 2009. Monetianthus mirus gen. et sp. nov., a nymphaealean flower from the Early Cretaceous of Portugal. Int. J. Pl. Sci. 170: 1086-1101. http://dx.doi.org/10.1086/605120

Friis, E.M., Grimm, G.W., Mendes, M.M. \& Pedersen, K.R. 2015. Canrightiopsis, a new Early Cretaceous fossil with Clavatipollenites-type pollen bridge the gap between extinct Canrightia and extant Chloranthaceae. Grana 54: 184-212. http://dx.doi.org/10.1080/00173134.2015.1060750

Galati, B.G. 1985. Estudios embriológicos en Cabomba australis (Nymphaeaceae) I. La esporogenesis y las generaciones sexuadas. Bol. Soc. Argent. Bot. 24: 29-47.

Galati, B.G., Rosenfeldt, S., Zarlawsky, G. \& Gotelli, M.M. 2015. Ultrastructure of the stigma and style of Cabomba caroliniana Gray (Cabombaceae). Protoplasma, on-line ahead of print. http://dx.doi.org/10.1007/s00709-015-0799-0

Goremykin, V.V., Nikiforova, S.V., Cavalieri, D., Pindo, M. \& Lockhart, P. 2015. The root of flowering plants and total evidence. Syst. Biol. 64: 879-891. http://dx.doi.org/10.1093/sysbio/syv028

Hamann, U. 1975. Neue Untersuchungen zur Embryologie und Systematik der Centrolepidaceae. Bot. Jahrb. Syst. 96: 154-191.

Hamann, U. 1976. Hydatellaceae - A new family of Monocotyledoneae. New Zealand J. Bot. 14: 193-196. http://dx.doi.org/10.1080/0028825X.1976.10428894

Heo, K., Van der Werff, H. \& Tobe, H. 1998. Embryology and relationships of Lauraceae (Laurales). Bot. J. Linn. Soc. 126: 295-322. http://dx.doi.org/10.1111/j.1095-8339.1998.tb01383.x

Igersheim, A. \& Endress, P.K. 1997. Gynoecium diversity and systematics of the Magnoliales and winteroids. Bot. J. Linn. Soc. 124: 213-271. http://dx.doi.org/10.1111/j.1095-8339.1997.tb01792.x

Igersheim, A. \& Endress, P.K. 1998. Gynoecium diversity and systematics of the paleoherbs. Bot. J. Linn. Soc. 127: 289-370. http://dx.doi.org/10.1111/j.1095-8339.1998.tb02102.x

Ito, M. 1986. Studies in the floral morphology and anatomy of Nymphaeales III. Floral anatomy of Brasenia schreberi Gmel. and Cabomba caroliniana A. Gray. Bot. Mag. (Tokyo) 99: 169-184. http://dx.doi.org/10.1007/BF02488818

Iwamoto, A., Shimizu, A. \& Ohba, H. 2003. Floral development and phyllotactic variation in Ceratophyllum demersum (Ceratophyllaceae). Amer. J. Bot. 90: 1124-1130. http://dx.doi.org/10.3732/ajb.90.8.1124

Jansen, R.K., Cai, Z., Raubeson, L.A., Daniell, H., dePamphilis, C.W., Leebens-Mack, J., Müller, K.F., Guisinger-Bellian, M., Haberle, R.C., Hansen, A.K., Chumley, T.W., Lee, S.-B., Peery, R., McNeal, J.R., Kuehl, J.V. \& Boore, J.L. 2007. Analysis of 81 genes from 64 plastid genomes resolves relationships in angiosperms and identifies genome-scale evolutionary patterns. Proc. Natl. Acad. Sci. U.S.A. 104: 19369-19374. http://dx.doi.org/10.1073/pnas.0709121104

Jędrychowska, A. \& Sroczyńska, A. 1934. On the cytology and embryology of Ceratophyllum submersum. Acta Soc. Bot. Poloniae 11: 423-441.

Jones, E.N. 1931. The morphology and biology of Ceratophyllum demersum. Stud. Nat. Hist. Iowa Univ. 13: 11-55.

Kimoto, Y.\& Tobe, H. 2003. Embryology of Siparunaceae (Laurales): characteristics and character evolution. J. Pl. Res. 116: 281-294. http://dx.doi.org/10.1007/s10265-003-0091-9

Leinfellner, W. 1969. Über die Karpelle verschiedener Magnoliales. VIII. Überblick über alle Familien der Ordnung. Österr. Bot. Z. 117: 107-127. http://dx.doi.org/10.1007/BF01379515
Leroy, J.-F. 1983. The origin of angiosperms: An unrecognized ancestral dicotyledon, Hedyosmum (Chloranthales), with a strobiloid flower is living today. Taxon 32: 169-175. http://dx.doi.org/10.2307/1221968

Lima, C.T., dos Santos, F.A.R. \& Giulietti, A.M. 2014. Morphological strategies of Cabomba (Cabombaceae), a genus of aquatic plants. Acta Bot. Brasil. 28: 327-338. http://dx.doi.org/10.1590/0102-33062014abb3439

Liu, Z., Hao, G., Luo, Y.-B., Thien, L.B., Rosso, S.W., Lu, A.-M. \& Chen, Z.-D. 2006. Phylogeny and androecial evolution in Schisandraceae, inferred from sequences of nuclear ribosomal DNA ITS and chloroplast DNA trnL-F regions. Int. J. Pl. Sci. 167: 539-550. http://dx.doi.org/10.1086/501476

Löhne, C., Yoo, M.-J., Borsch, T., Wiersema, J., Wilde, V., Bell, C.D., Barthlott, W., Soltis, D.E. \& Soltis, P.S. 2008. Biogeography of Nymphaeales: Extant patterns and historical events. Taxon 57: 1123-1146. http://www.jstor.org/stable/27756769

Luo, Y.-B. \& Li, Z.Y. 1999. Pollination ecology of Chloranthus serratus (Thunb.) Roem. et Schult. and Ch. fortunei (A. Gray) Solms-Laub. (Chloranthaceae). Ann. Bot. (Oxford) 83: 489-499. http://dx.doi.org/10.1006/anbo.1998.0845

Lyew, J., Li, Z., Yuan, L.-C., Luo, Y.-B. \& Sage, T.L. 2007. Pollen tube growth in association with a dry-type stigmatic transmitting tissue and extragynoecial compitum in the basal angiosperm Kadsura longipedunculata (Schisandraceae). Amer. J. Bot. 94: 1170-1182. http://dx.doi.org/10.3732/ajb.94.7.1170

Ma, S.-B., Wang, Y.-H. \& Cui, M.-K. 1997. A contribution to the reproductive biology of Chloranthus holostagius (Chloranthaceae) in Mile population. Acta Bot. Yunnan. 19: 415-422.

Maddison, D.R. \& Maddison, W.P. 2003. MacClade 4: Analysis of phylogeny and character evolution, version 4.06. Sunderland, Massachusetts: Sinauer.

Maekawa, F. 1970. Notes on the stamens of Chloranthus japonicus. J. Jap. Bot. 45: 289-294.

Mathews, S. \& Donoghue, M.J. 1999. The root of angiosperm phylogeny inferred from duplicate phytochrome genes. Science 286: 947-950. http://dx.doi.org/10.1126/science.286.5441.947

Mathur, S.L. 1968. Development of the male and female gametophytes of Calycanthus fertilis Walt. Proc. Natl. Inst. Sci. India, B 34: 323-329.

Meeuse, A.D.J. 1972. Facts and fiction in floral morphology with special reference to the Polycarpicae 1. A general survey. Acta Bot. Neerl. 21: 113-127. http://dx.doi.org/10.1111/j.1438-8677.1972.tb00755.x

Moore, L.B. 1977. The flowers of Ascarina lucida Hook. f. (Chloranthaceae). New Zealand J. Bot. 15: 491-494. http://dx.doi.org/10.1080/0028825X.1977.10432555

Moore, M.J., Bell, C.D., Soltis, P.S. \& Soltis, D.E. 2007. Using plastid genome-scale data to resolve enigmatic relationships among basal angiosperms. Proc. Natl. Acad. Sci. U.S.A. 104: 19363-19368. http://dx.doi.org/10.1073/pnas.0708072104

Moore, M.J., Hassan, N., Gitzendanner, M.A., Bruenn, R.A., Croley, M., Vandeventer, A., Horn, J.W., Dhingra, A., Brockington, S.F., Latvis, M., Ramdial, J., Alexandre, R., Piedrahita, A., Xi, Z., Davis, C.C., Soltis, P.S. \& Soltis, D.E. 2011. Phylogenetic analysis of the plastid inverted repeat for 244 species: Insights into deeper-level angiosperm relationships from a long, slowly evolving sequence region. Int. J. Pl. Sci. 172: 541-558. http://dx.doi.org/10.1086/658923

Omland, K.E., Cook, L.G. \& Crisp, M.D. 2008. Tree thinking for all biology: The problem with reading phylogenies as ladders of progress. Bioessays 30: 854-867. http://dx.doi.org/10.1002/bies.20794

Omori, Y. 2003. Floral anatomy of Sarcandra glabra (Thunb.) Nakai (Chloranthaceae): Reevaluation of the hypothesis that the flower of Sarcandra was derived from an inflorescence. Sci. Rep. Yokosuka City Mus. 50: 21-32. 
Orban, I. \& Bouharmont, J. 1998. Megagametophyte development of Nymphaea nouchali Burm. f. (Nymphaeaceae). Bot. J. Linn. Soc. 126: 339-348. http://dx.doi.org/10.1111/j.1095-8339.1998.tb01386.x

Osborn, J.M. \& Schneider, E.L. 1988. Morphological studies of the Nymphaeaceae sensu lato. XVI. The floral biology of Brasenia schreberi. Ann. Missouri Bot. Gard. 75: 778-794. http://dx.doi.org/10.2307/2399366

Parkinson, C.L., Adams, K.L. \& Palmer, J.D. 1999. Multigene analyses identify the three earliest lineages of extant flowering plants. Curr. Biol. 9: 1485-1488. http://dx.doi.org/10.1016/S0960-9822(00)80119-0

Perkins, J. 1925. Übersicht über die Gattungen der Monimiaceae sowie Zusammenstellung der Abbildungen und der Literatur über die Arten dieser Familie bis zum Jahre 1925. Leipzig: Engelmann.

Posluszny, U. \& Tomlinson, P.B. 2003. Aspects of inflorescence and floral development in the putative basal angiosperm Amborella trichopoda (Amborellaceae). Canad. J. Bot. 81: 28-39. http://dx.doi.org/10.1139/b03-004

Povilus, R.A., Losada, J.M. \& Friedman, W.E. 2015. Floral biology and ovule and seed ontogeny of Nymphaea thermarum, a water lily at the brink of extinction with potential as a model system for basal angiosperms. Ann. Bot. (Oxford) 115: 211-226. http://dx.doi.org/10.1093/aob/mcu235

Prance, G.T. \& Anderson, A.B. 1977. Studies on the floral biology of the neotropical Nymphaeaceae. 3. Acta Amazon. 6: 163-170.

Prance, G.T. \& Arias, J.R. 1975. A study of the floral biology of Victoria amazonica (Poepp.) Sowerby (Nymphaeaceae). Acta Amazon. 5: 109-139.

Prychid, C.J., Sokoloff, D.D. \& Remizowa, M.V., Tuckett, R.E., Yadav, S.R. \& Rudall, P.J. 2011. Unique stigmatic hairs and pollen-tube growth within the stigmatic cell wall in the earlydivergent angiosperm family Hydatellaceae. Ann. Bot. (Oxford) 108: 599-608. http://dx.doi.org/10.1093/aob/mcr021

Qiu, Y.-L., Lee, J., Bernasconi-Quadroni, F., Soltis, D.E., Soltis, P.S., Zanis, M.J., Zimmer, E.A., Chen, Z., Savolainen, V. \& Chase, M.W. 1999. The earliest angiosperms: Evidence from mitochondrial, plastid, and nuclear genomes. Nature 402: 404-407. http://dx.doi.org/10.1038/46536

Qiu, Y.-L., Li, L., Hendry, T.A., Li, R., Taylor, D.W., Issa, M.J., Ronen, A.J., Vekaria, M.L. \& White, A.M. 2006. Reconstructing the basal angiosperm phylogeny: Evaluating information content of mitochondrial genes. Taxon 55: 837-856. http://dx.doi.org/10.2307/25065680

Qiu, Y.-L., Li, L., Wang, B., Xue, J.-Y., Hendry, T.A., Li, R.-Q., Brown, J.W., Liu, Y., Hudson, G.T. \& Chen, Z.-D. 2010. Angiosperm phylogeny inferred from sequences of four mitochondrial genes. J. Syst. Evol. 48: 391-425. http://dx.doi.org/10.1111/j.1759-6831.2010.00097.x

Rataj, K. 1977. Uma nova Cabomba do rio Negro, Amazonas, Brazil. Acta Amazon. 7: 143.

Romanov, M.S., Bobrov, A.V.F.C. \& Endress, P.K. 2013. Structure of the unusual explosive fruits in the early diverging angiosperm Illicium (Schisandraceae s.l., Austrobaileyales). Bot. J. Linn. Soc. 171: 640-654. http://dx.doi.org/10.1111/boj.12003

Ronse De Craene, L.P., Soltis, P.S. \& Soltis, D.E. 2003. Evolution of floral structures in basal angiosperms. Int. J. Pl. Sci. 164(Suppl.): S329-S363. http://dx.doi.org/10.1086/377063

Rothwell, G.W., Crepet, W.L. \& Stockey, R.A. 2009. Is the anthophyte hypothesis alive and well? New evidence from the reproductive structures of Bennettitales. Amer. J. Bot. 96: 296-322. http://dx.doi.org/10.3732/ajb.0800209

Rudall, P.J., Sokoloff, D.D., Remizowa, M.V., Conran, J.G., Davis, J.I., Macfarlane, T.D. \& Stevenson, D.W. 2007. Morphology of Hydatellaceae, an anomalous aquatic family recently recognized as an early-divergent angiosperm lineage. Amer. J. Bot. 94: 1073-1092. http://dx.doi.org/10.3732/ajb.94.7.1073

Rudall, P.J., Remizowa, M.V., Beer, A.S., Bradshaw, E., Stevenson,
D.W., Macfarlane, T.D., Tuckett, R.E., Yadav, S.R. \& Sokoloff, D.D. 2008. Comparative ovule and megagametophyte development in Hydatellaceae and water lilies reveal a mosaic of features among the earliest angiosperms. Ann. Bot. (Oxford) 101: 941-956. http://dx.doi.org/10.1093/aob/mcn032

Rudall, P.J., Remizowa, M.V., Prenner, G., Prychid, C.J., Tuckett, R.E. \& Sokoloff, D.D. 2009. Nonflowers near the base of extant angiosperms? Spatiotemporal arrangement of organs in reproductive units of Hydatellaceae and its bearing on the origin of the flower. Amer. J. Bot. 96: 67-82. http://dx.doi.org/10.3732/ajb.0800027

Saarela, J.M., Rai, H.S., Doyle, J.A., Endress, P.K., Mathews, S., Marchant, A.D., Briggs, B.G. \& Graham, S.W. 2007. Hydatellaceae identified as a new branch near the base of the angiosperm phylogenetic tree. Nature 446: 312-315. http://dx.doi.org/10.1038/nature05612

Saunders, R.M.K. 2000. Monograph of Schisandra (Schisandraceae). Syst. Bot. Monogr. 58: 1-146. http://dx.doi.org/10.2307/25027879

Sauquet, H., von Balthazar, M., Magallón, S., Doyle, J.A., Endress, P.K., Bailes, E., Morais, E.B., Bull-Herenu, K., Carrive, L., Chartier, M., Chomicki, G., Coiro, M., El Ottra, J.H.L., Epicoco, C., Haevermans, T., Jabbour, F., Hernandez, R., Little, S.A., Löfstrand, S., Luna, J.A., Massoni, J., Nadot, S., Prieu, C., Reyes, E., dos Santos, P., Schoonderwoerd, K., Soulebeau, A., Staedler, Y., Tschan, G., Leung, W.-S.A. \& Schoenenberger, J. 2015. Fifteen clues to the early diversification of flowers: First results from the eFlower initiative. Botany 2015, Abstract 470. http://2015.botanyconference.org/engine/search/index. php? func $=$ detail $\&$ aid $=470$

Schmucker, T. 1932. Physiologische und ökologische Untersuchungen an Blüten tropischer Nymphaea-Arten. Planta 16: 376-412. http://dx.doi.org/10.1007/BF01911473

Schneider, E.L. 1976. The floral anatomy of Victoria Schomb. (Nymphaeaceae). Bot. J. Linn. Soc. 72: 115-148. http://dx.doi.org/10.1111/j.1095-8339.1976.tb01355.x

Schneider, E.L. 1978. Morphological studies of the Nymphaeaceae. IX. The seed of Barclaya longifolia Wall. Bot. Gaz. 139: 223-230. http://dx.doi.org/10.1086/336993

Schneider, E.L. \& Jeter, J.M. 1982. Morphological studies of the Nymphaeaceae. XII. The floral biology of Cabomba caroliniana. Amer. J. Bot. 69: 1410-1419. http://dx.doi.org/10.2307/2443102

Schneider, E.L. \& Williamson, P.S. 1993. Nymphaeaceae. Pp. 486-493 in: Kubitzki, K., Rohwer, J.G. \& Bittrich, V. (eds.), The families and genera of vascular plants, vol. 2. Berlin: Springer. http://dx.doi.org/10.1007/978-3-662-02899-5 57

Schneider, E.L., Tucker, S.C. \& Williamson, P.S. 2003. Floral development in the Nymphaeales. Int. J. Pl. Sci. 164(Suppl.): S279-S292. http://dx.doi.org/10.1086/376883

Sehgal, A. \& Ram, H.Y.M. 1981. Comparative developmental morphology of two populations of Ceratophyllum L. (Ceratophyllaceae) and their taxonomy. Bot. J. Linn. Soc. 82: 343-356. http://dx.doi.org/10.1111/j.1095-8339.1981.tb00966.x

Shamrov, I.I. 1983. Antèkologičeskoe issledovanie treh vidov roda Ceratophyllum (Ceratophyllaceae) [Anthecological investigation of three species of the genus Ceratophyllum (Ceratophyllaceae)]. Bot. Zhurn. (Moscow \& Leningrad) 68: 1357-1365.

Shamrov, I.I. 1997. Razvitie semâzačatka i semeni u Ceratophyllum demersum [Ovule and seed development in Ceratophyllum demersum (Ceratophyllaceae)]. Bot. Zhurn. (St. Petersburg) 82(10): 1-12.

Shamrov, I.I. 2009. Morfologičeskaâ priroda gineciâ i ploda u Ceratophyllum [The morphological nature of gynoecium and fruit in Ceratophyllum (Ceratophyllaceae)]. Bot. Zhurn. (St. Petersburg) 94: 938-961.

Skubatz, H., Williamson, P.S., Schneider, E.L. \& Meeuse, B.J.D. 1990. Cyanide-insensitive respiration in thermogenic flowers of Victoria and Nelumbo. J. Exp. Bot. 41: 1335-1339. http://dx.doi.org/10.1093/jxb/41.10.1335 
Sokoloff, D.D., Remizowa, M.V., Macfarlane, T.D. \& Rudall, P.J. 2008. Classification of the early-divergent angiosperm family Hydatellaceae: One genus instead of two, four new species and sexual dimorphism in dioecious taxa. Taxon 57: 179-200.

Sokoloff, D.D., Remizowa, M.V., Macfarlane, T.D., Conran, J.G., Yadav, S.R. \& Rudall, P.J. 2013. Comparative fruit structure in Hydatellaceae (Nymphaeales) reveals specialized pericarp dehiscence in some early-divergent angiosperms with ascidiate carpels. Taxon 62: 40-61.

Soltis, D.E., Soltis, P.S., Endress, P.K. \& Chase, M.W. 2005. Phylogeny and evolution of angiosperms. Sunderland, Massachusetts: Sinauer.

Soltis, D.E., Soltis, P.S., Chase, M.W., Mavrodiev, E.V., Majure, L.C., Endress, P.K., Judd, W.S. \& Manchester, S.R. In press. Phylogeny and evolution of the angiosperms, revised and updated edition. Chicago: University of Chicago Press.

Soltis, P.S., Soltis, D.E. \& Chase, M.W. 1999. Angiosperm phylogeny inferred from multiple genes as a tool for comparative biology. Nature 402: 402-404. http://dx.doi.org/10.1038/46528

Staedler, Y.M. \& Endress, P.K. 2009. Diversity and lability of floral phyllotaxis in the pluricarpellate families of core Laurales (Gomortegaceae, Atherospermataceae, Siparunaceae, Monimiaceae). Int. J. Pl. Sci. 170: 522-550. http://dx.doi.org/10.1086/597272

Strasburger, E. 1902. Ein Beitrag zur Kenntniss von Ceratophyllum submersum und phylogenetische Erörterungen. Jahrb. Wiss. Bot. 37: 477-526.

Sun, M., Soltis, D.E., Soltis, P.S., Zhu, X., Burleigh, J.G. \& Chen, Z. 2015. Deep phylogenetic incongruence in the angiosperm clade Rosidae. Molec. Phylogen. Evol. 83: 156-166. http://dx.doi.org/10.1016/j.ympev.2014.11.003

Swamy, B.G.L. 1964. Macrogametophytic ontogeny in Schisandra chinensis. J. Indian Bot. Soc. 43: 391-396.

Taylor, E.L. \& Taylor, T.N. 2009. Seed ferns from the late Paleozoic and Mesozoic: Any angiosperm ancestors lurking there? Amer. J. Bot. 96: 237-251. http://dx.doi.org/10.3732/ajb.0800202

Taylor, M.L. \& Williams, J.H. 2009. Consequences of pollination syndrome evolution for postpollination biology in an ancient angiosperm family. Int. J. Pl. Sci. 170: 584-598. http://dx.doi.org/10.1086/597269

Taylor, M.L. \& Williams, J.H. 2012. Pollen tube development in two species of Trithuria (Hydatellaceae) with contrasting breeding systems. Sexual Pl. Reprod. 25: 83-96. http://dx.doi.org/10.1007/s00497-012-0183-6

Thien, L.B., Azuma, H. \& Kawano, S. 2000. New perspectives on the pollination biology of basal angiosperms. Int. J. Pl. Sci. 161(Suppl.): S225-S235. http://dx.doi.org/10.1086/317575

Tobe, H., Jaffré, T. \& Raven, P.H. 2000. Embryology of Amborella (Amborellaceae): Descriptions and polarity of character states. J. Pl. Res. 113: 271-280. http://dx.doi.org/10.1007/PL00013935

Tobe, H., Kimoto, Y. \& Prakash, N. 2007. Development and structure of the female gametophyte in Austrobaileya scandens (Austrobaileyaceae). J. Pl. Res. 120: 431-436. http://dx.doi.org/10.1007/s10265-007-0085-0

Todzia, C.A. 1988. Chloranthaceae: Hedyosmum. Fl. Neotrop. Monogr. 48: $1-139$

Van der Vlugt, P.J. 1996. Erfahrungen mit Brasenia schreberi J.F. Gmelin. Aqua Pl. 21: 3-10.

Van Miegroet, F. \& Dujardin, M. 1992. Cytologie et histologie de la reproduction chez le Nymphaea heudelotii. Canad. J. Bot. 70: 1991-1996. http://dx.doi.org/10.1139/b92-247

Von Balthazar, M. \& Endress, P.K. 1999. Floral bract function, flowering process and breeding systems of Sarcandra and Chloranthus (Chloranthaceae). Pl. Syst. Evol. 218: 161-178. http://dx.doi.org/10.1007/BF01089225

Vijayaraghavan, M.R. 1964. Morphology and embryology of a vesselless dicotyledon - Sarcandra irvingbaileyi Swamy, and systematic position of the Chloranthaceae. Phytomorphology 14: 429-441.
Wang, Y.-H., Ma, S.-B. \& Cui, M.-K. 1998. The characteristics of reproductive biology of Chloranthus holostagius. J. Yunnan Univ. (Nat. Sci. Ed.) 1998: S4.

Wiersema, J.H. 1988. Reproductive biology of Nymphaea (Nymphaeaceae). Ann. Missouri Bot. Gard. 75: 795-804. http://dx.doi.org/10.2307/2399367

Williams, J.H. 2008. Novelties of the flowering plant pollen tube underlie diversification of a key life history stage. Proc. Natl. Acad. Sci. U.S.A. 105: 11259-11263. http://dx.doi.org/10.1073/pnas.0800036105

Williams, J.H. 2009. Developmental evolution of the progamic phase: Amborella trichopda (Amborellaceae). Amer. J. Bot. 96: 144-165. http://dx.doi.org/10.3732/ajb.0800070

Williams, J.H. 2012. The evolution of pollen germination timing in flowering plants: Austrobaileya scandens (Austrobaileyaceae). AoB Plants 2012: pls010. http://dx.doi.org/10.1093/aobpla/pls010

Williams, J.H. \& Friedman, W.E. 2002. Identification of diploid endosperm in an early angiosperm lineage. Nature 415: 522-525. http://dx.doi.org/10.1038/415522a

Williams, J.H. \& Friedman, W.E. 2004. The four-celled female gametophyte of Illicium (Illiciaceae; Austrobaileyales): Implications for understanding the origin and early evolution of monocots, eudicots, and eumagnoliids. Amer. J. Bot. 91: 332-351. http://dx.doi.org/10.3732/ajb.91.3.332

Williams, J.H., McNeilage, R.T., Lettre, M.T. \& Taylor, M.L. 2010 Pollen tube growth and the pollen-tube pathway of Nymphaea odorata (Nymphaeaceae). Bot. J. Linn. Soc. 162: 581-593. http://dx.doi.org/10.1111/j.1095-8339.2010.01039.x

Williamson, P.S. \& Schneider, E.L. 1993. Cabombaceae. Pp. 157-161 in: Kubitzki, K., Rohwer, J.G. \& Bittrich, V. (eds.), The families and genera of vascular plants, vol. 2. Berlin: Springer. http://dx.doi.org/10.1007/978-3-662-02899-5 16

Winter, A.N. 1993. Nekotorye aspekty reproduktivnoj biologii Hydrostemma longifolium (Barclaya longifolia) (Barclayaceae) [Some aspects of the reproductive biology of Hydrostemma longifolium (Barclaya longifolia) (Barclayaceae)]. Bot. Zhurn. (St. Petersburg) 78 (1): 69-83.

Winter, A.N. \& Shamrov, I.I. 1991a. Megasporogenez i razvitie zarodyševogo meška u predstavitelej rodov Nymphaea i Victoria (Nymphaeaceae) [Megasporogenesis and embryo sac development in representatives of the genera Nymphaea and Victoria (Nymphaeaceae)]. Bot. Zhurn. (Moscow \& Leningrad) 76: 1716-1728.

Winter, A.N. \& Shamrov, I.I. 1991b. Razvitie semâzačatka i zarodyševogo meška u Nuphar lutea (Nymphaeaceae) [The development of the ovule and embryo sac in Nuphar lutea (Nymphaeaceae)]. Bot. Zhurn. (Moscow \& Leningrad) 76: 378-390.

Xi, Z., Liu, L., Rest, J.S. \& Davis, C.C. 2014. Coalescent versus concatenation methods and the placement of Amborella as sister to water lilies. Syst. Biol. 63: 919-932. http://dx.doi.org/10.1093/sysbio/syu055

Yamada, T., Tobe, H., Imaichi, R. \& Kato, M. 2001. Developmental morphology of the ovules of Amborella trichopoda (Amborellaceae) and Chloranthus serratus (Chloranthaceae). Bot. J. Linn. Soc. 137: 277-290. http://dx.doi.org/10.1111/j.1095-8339.2001.tb01123.x

Yatzenko, I.O., Melikian, A.P., Bobrov, A.V.F.C. \& Romanov, M.S. 2012. Struktura plodov nimfejnyh: Karpologičeskaâ točka zreniâ na sestrinskoe položenie Nymphaeaceae s.l. po otnošeniû ko vsem ostal'nym pokrytosemennym (isklûčaâ Amborella) [Fruit structure in water lily family: Carpological point of view on sister position of Nymphaeaceae s.l. to all other angiosperms (except Amborella)]. Byull. Moskovsk. Obshch. Isp. Prir., Otd. Biol. 117: 33-43.

Yoo, M.-J., Bell, C.D., Soltis, P.S. \& Soltis, D.E. 2005. Divergence times and historical biogeography of Nymphaeales. Syst. Bot. 30: 693-704. http://dx.doi.org/10.1600/036364405775097798

Yoshida, O. 1957. Embryologische Studien über die Ordnung Piperales I. Embryologie von Chloranthus japonicus Sieb. J. Coll. Arts Sci. Chiba Univ. 2: 172-178. 
Yoshida, O. 1959. Embryologische Studien über die Ordnung Piperales II. Embryologie von Chloranthus serratus Roem. et Schult. J. Coll. Arts Sci. Chiba Univ. 2: 295-303.

Yoshida, O. 1960. Embryologische Studien über die Ordnung Piperales III. Embryologie von Sarcandra glabra Nakai. J. Coll. Arts Sci. Chiba Univ. 3: 55-60.

Zeng, L., Zhang, Q., Sun, R., Kong, H., Zhang, N. \& Ma, H. 2014. Resolution of deep angiosperm phylogeny using conserved nuclear genes and estimates of early divergence times. Nature Commun. 5: 4956. http://dx.doi.org/10.1038/ncomms5956
Zhang, N.L., Zeng, L., Shan, H. \& Ma, H. 2012. Highly conserved low-copy nuclear genes as effective markers for phylogenetic analyses in angiosperms. New Phytol. 195: 923-937. http://dx.doi.org/10.1111/j.1469-8137.2012.04212.x

Zini, L.M., Galati, B.G. \& Ferrucci, M.S. 2015. Ovule and female gametophyte in representatives of Nymphaea subgenus Hydrocallis and Victoria (Nymphaeaceae; Nymphaeoideae). Aquatic Bot. 120: 322-332. http://dx.doi.org/10.1016/j.aquabot.2014.09.012

Appendix 1. Species and specimens used for the Figures.

Amborella trichopoda Baill. (Amborellaceae), cult. Santa Cruz Arboretum, University of California, Santa Cruz, no voucher, coll. Sep 1993, forwarded

by H. Tobe (Fig. 5H); H.S. MacKee 38909, New Caledonia (Fig. 7A); cult. BGZ, grown from fruits collected by H.S. MacKee 38408, New Caledonia

(Fig. 8A-B); H.S. Mac Kee 38907, New Caledonia (Fig. 8C-D)

Ascarina rubricaulis Solms (Chloranthaceae), male: PKE 6012, New Caledonia (Fig. 11E); female: PKE 6013, New Caledonia (Fig. 11F)

Austrobaileya scandens C.T.White (Austrobaileyaceae), all Northern Queensland, Australia, B. Gray 2044 (Fig. 5N); PKE 4265 (Fig. 10D, E); cult. BGZ and

Botanic Garden of the University of Bonn, both grown from fruits coll. by PKE 9083 (Fig. 10A-C)

Cabomba caroliniana A.Gray (Cabombaceae), PKE s.n., s.d., cult. BGZ (Fig. 8F)

C. furcata Schult. \& Schult.f., PKE 00-58, cult. BGZ (Figs. 5L, 8E)

Ceratophyllum demersum L. (Ceratophyllaceae), all cult. BGZ, PKE 9755 (Fig. 5K); PKE 9851 (Fig. 12C); PKE 9852 (Figs. 7E, 12D); PKE 9853 (Fig. 12B); PKE s.n., s.d. (Fig. 12A)

Chloranthus erectus (Buch.-Ham.) Verdc. (Chloranthaceae), PKE 4078, Papua New Guinea (Figs. 5J, 7D, 11I)

C. serratus (Thunb.) Roem. \& Schult., PKE, s.n., s.d., cult. BGZ (Fig. 11H)

C. spicatus (Thunb.) Makino, PKE 6740, cult. BGZ (Fig. 11G)

Hedyosmum costaricense C.E.Wood. ex W.C.Burger (Chloranthaceae), PKE 97-107, Costa Rica (Fig. 11A-B)

H. mexicanum C.Cordem., PKE 1114, Honduras (Fig. 11C)

Illicium floridanum J.Ellis (Schisandraceae), PKE s.n., s.d., BGZ (Fig. 10L)

I. lanceolatum A.C.Smith, PKE s.n., s.d., BGZ (Fig. 10K)

Kadsura japonica (L.) Dunal (Schisandraceae), PKE s.n., s.d., BGZ (Fig. 10G-J)

Laurus nobilis L. (Lauraceae), PKE 2639, cult. Switzerland (Fig. 5C)

Nuphar advena (Aiton) W.T.Aiton (Nymphaeaceae), PKE 00-61, BGZ (Fig. 8G)

Nymphaea tetragona Georgi (Nymphaeaceae), PKE s.n., s.d., BGZ (Fig. 8H)

Sarcandra chloranthoides Gardner (Chloranthaceae), PKE s.n., s.d., BGZ, grown from fruits collected by K.U. Kramer 6582 (Fig. 11D)

Trimenia moorei (Oliv.) Philipson (Trimeniaceae), PKE 4367, New South Wales, Australia (Fig. 10F)

T. neocaledonica Baker f., PKE 6315, New Caledonia (Fig. 7C)

T. papuana Ridl., PKE 4087, Papua New Guinea (Fig. 5I)

Victoria cruziana A.D.Orb. (Nymphaeaceae), PKE 9983, BGZ (Fig. 5M)

Abbreviations: BGZ, cultivated, Botanic Garden, University of Zurich; PKE, collected by Peter K. Endress. 